\title{
Gunite and Associated Tanks \\ Treatability Study Equipment Testing at the Tanks Technology Cold Test Facility
}

February 2000

Prepared by

B. L. Burks 


DOCUMENT AVAILABILITY
Reports produced after January 1, 1996, are generally available free via the U. S. Department of
Energy (DOE) Information Bridge.
Web site http://www.osti.gov/bridge
Reports produced before January 1,1996, may be purchased by members of the public from the
following source.
National Technical Information Services
5285 Port Royal Road
Springfield, VA 22161
Telephone 703-605-6000 (1-800-53-6847)
TDD 703-487-4639
Fax 703-605-6900
E-mail info@ntis.fedworld.gov
Web site http://www.ntis.gov/support/ordernowabout.htm
Reports are available to DOE employees, DOE contractors, Energy Technology Data Exchange
(ETDE) representatives, and International Nuclear Information System (INIS) representatives from
the following source.
Office of Scientific and Technical Information
P.O. Box 62
Oak Ridge, TN 37831
Telephone 865-576-8401
Fax 865-576-5728
E-mail reports@adonis.osti.gov
Web site http://www.osti.gov/contact.html

This report was prepared as an account of work sponsored by an agency of the
United States Government. Neither the United States government nor any
agency thereof, nor any of their employees, makes any warranty, express or
implied, or assumes any legal liability or responsibility for the accuracy,
completeness, or usefulness of any information, apparatus, product, or process
disclosed, or represents that its use would not infringe privately owned rights.
Reference herein to any specific commercial product, process, or service by
trade name, trademark, manufacturer, or otherwise, does not necessarily
constitute or imply its endorsement, recommendation, or favoring by the United
States Government or any agency thereof. The views and opinions of authors
expressed herein do not necessarily state or reflect those of the United States
Government or any agency thereof.


ORNL/TM-13629

\title{
GUNITE AND ASSOCIATED TANKS TREATABILITY STUDY EQUIPMENT TESTING AT THE \\ TANKS TECHNOLOGY COLD TEST FACILITY
}

Oak Ridge National Laboratory

Environmental Restoration Program

Robotics Technology Development Program

Tanks Focus Area

Date Published: February 2000
B. L. Burks
S. M. Babcock
D. C. Dunning
C. L. Fitzgerald
W. H. Glover
S. M. Killough
P. D. Lloyd
V. Rule
J. E. Rutenber

\author{
J. Blank \\ D. D. Falter \\ R. L. Glassell \\ D. E. Hobson \\ D. J. Kington \\ J. D. Randolph \\ R. Russell \\ H. Toy \\ S. D. Van Hoesen
}

Prepared by

OAK RIDGE NATIONAL LABORATORY

P.O. Box 2008

Oak Ridge, Tennessee 37831-6285

managed by

UT-Battelle, LLC,

for the

U.S. DEPARTMENT OF ENERGY

under contract DE-AC05-00OR22725 


\section{CONTENTS}

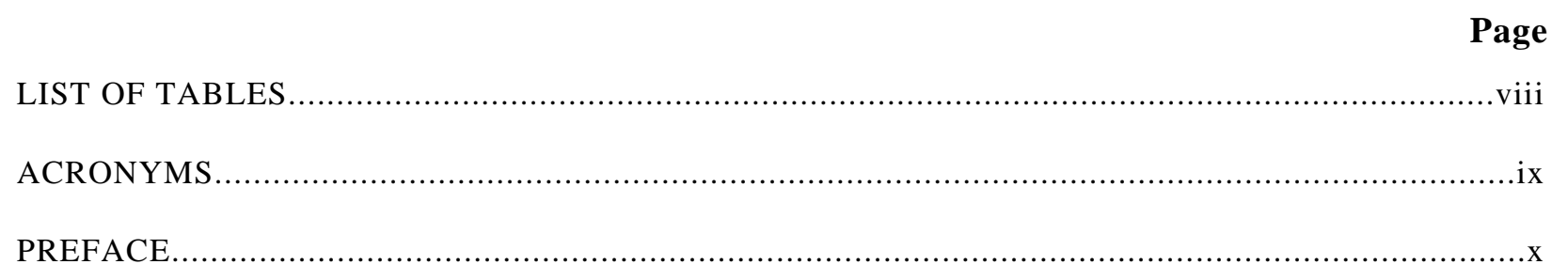

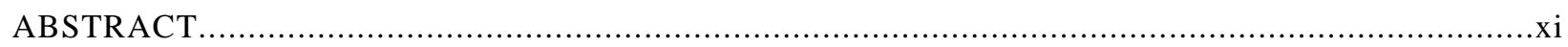

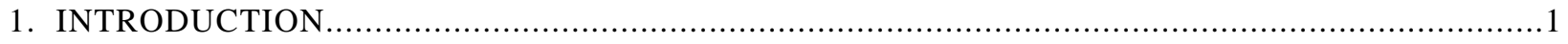

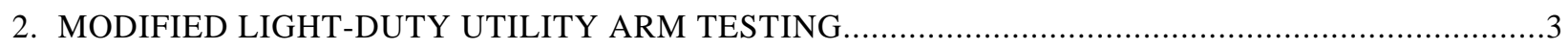

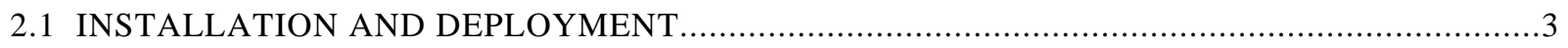

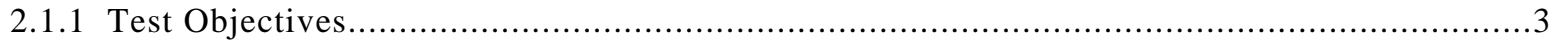

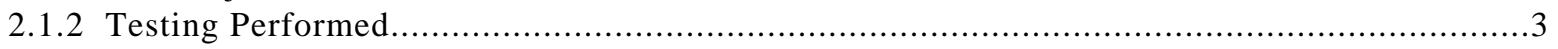

2.1.2.1 Riser extension and Tank Riser Interface and Containment (TRIC) installation..........................

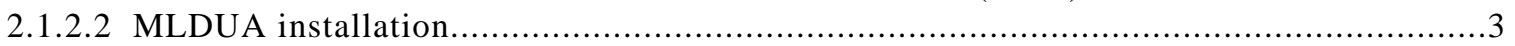

2.1.2.3 MLDUA testing with pendant controller............................................................

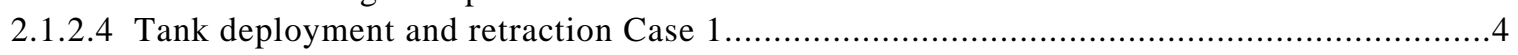

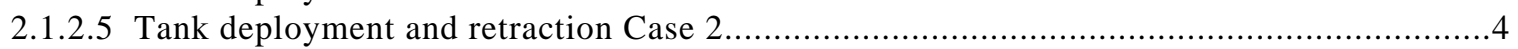

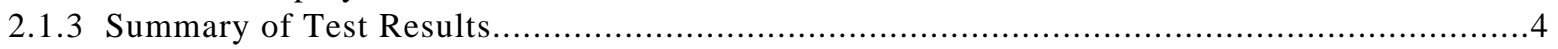

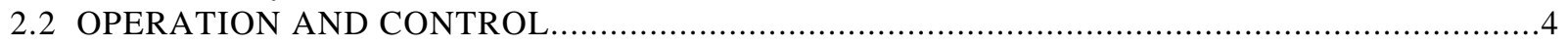

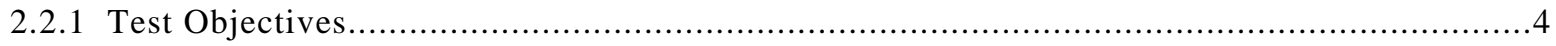

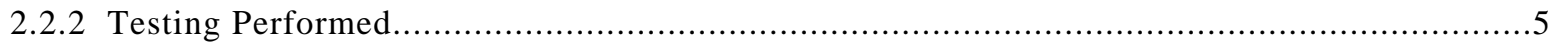

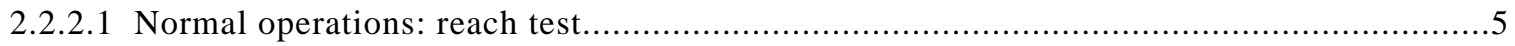

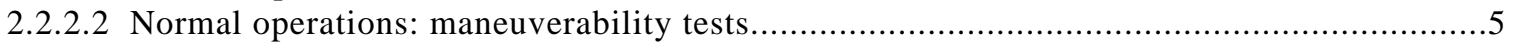

2.2.2.3 Normal operations: payload/maneuverability test.....................................................

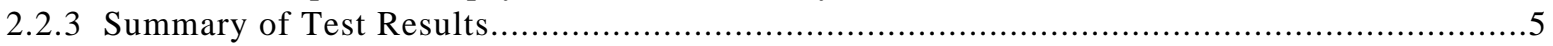

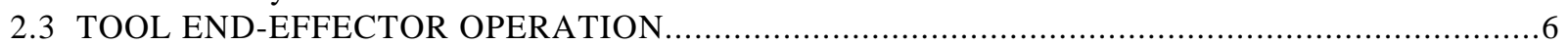

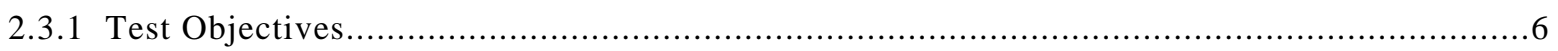

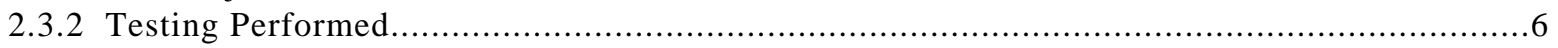

2.3.2.1 Characterization end effector (CEE) changeout and operations............................................6

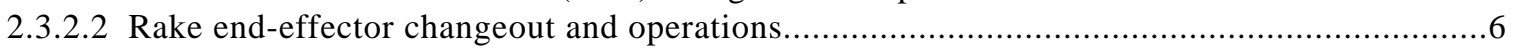

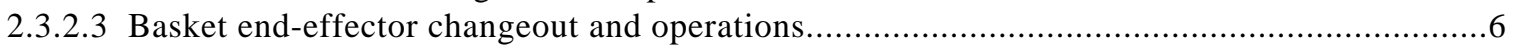

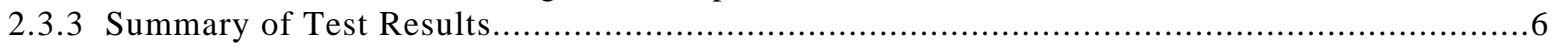

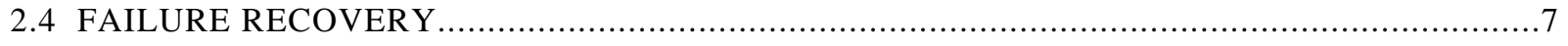

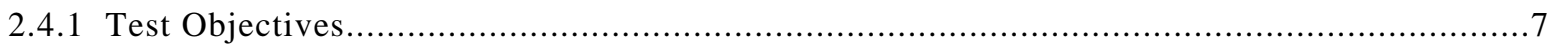

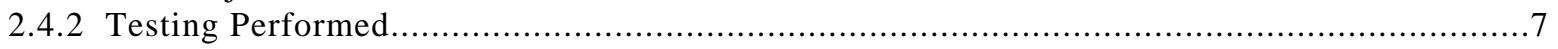

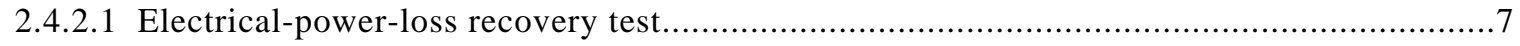

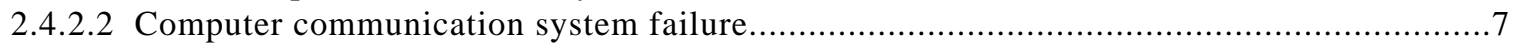

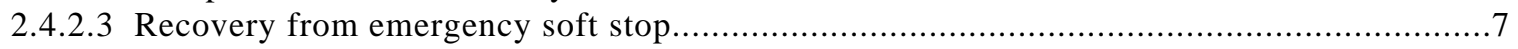

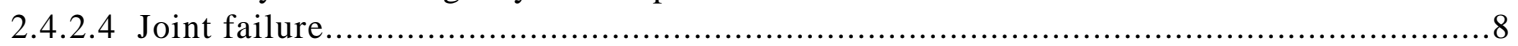

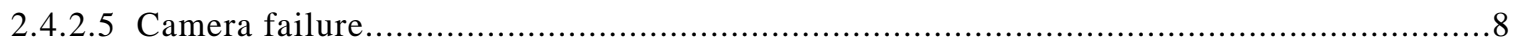

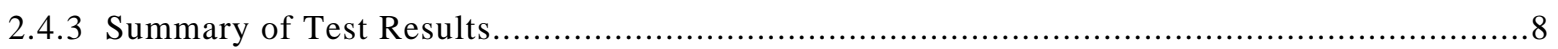

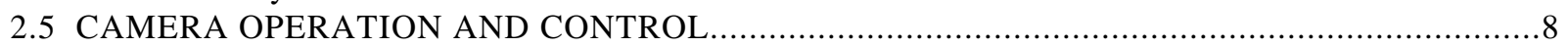

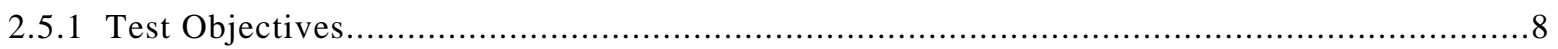

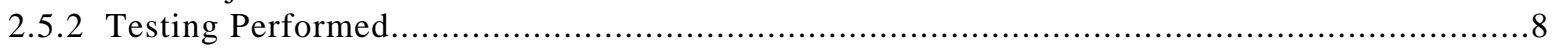

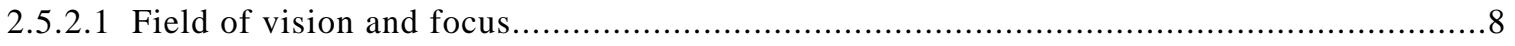

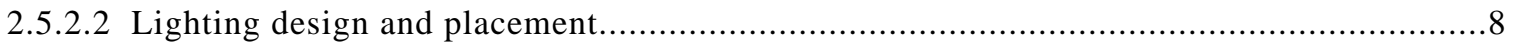

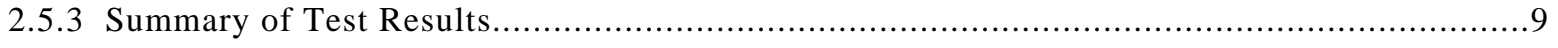

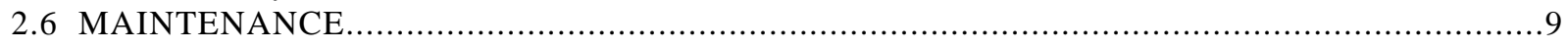

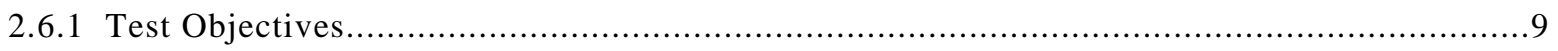

- iii - 


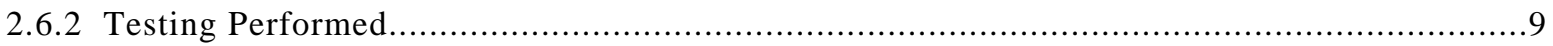

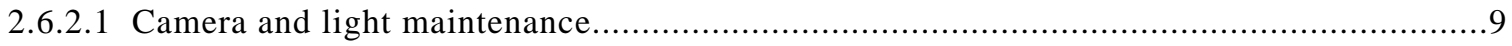

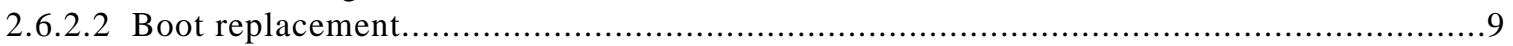

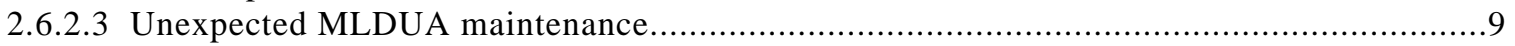

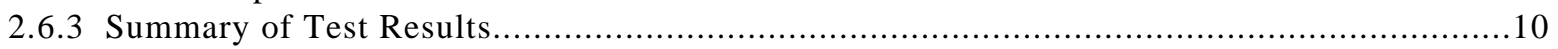

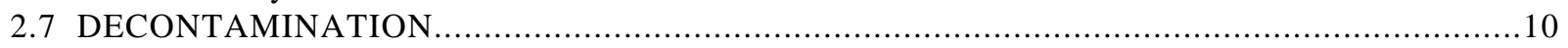

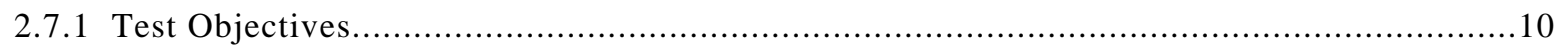

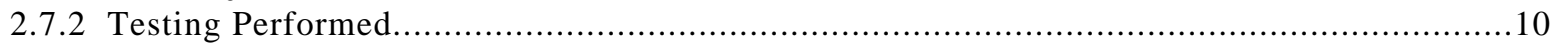

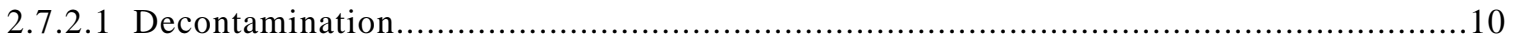

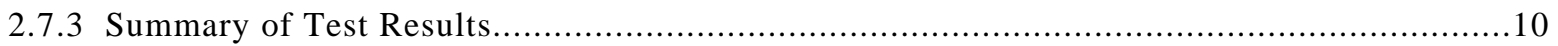

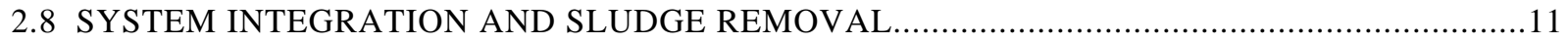

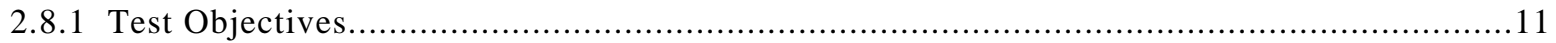

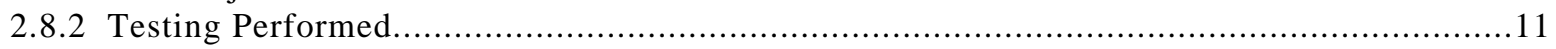

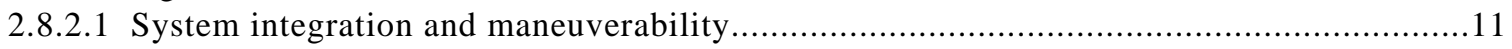

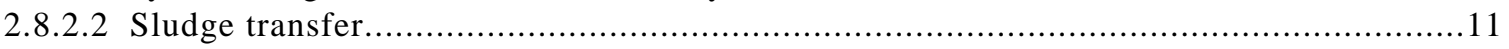

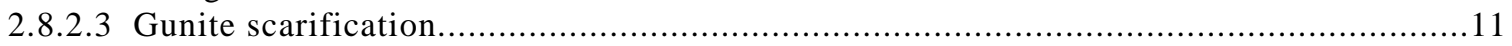

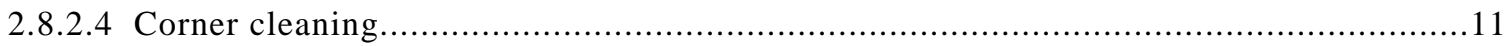

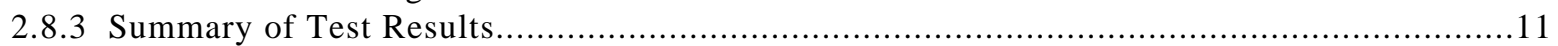

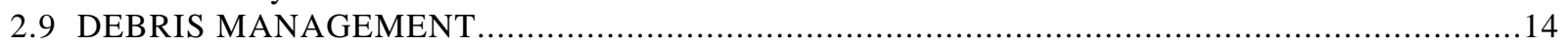

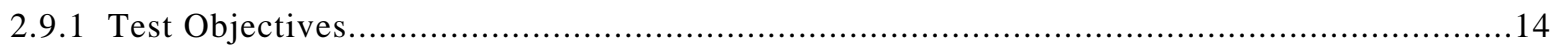

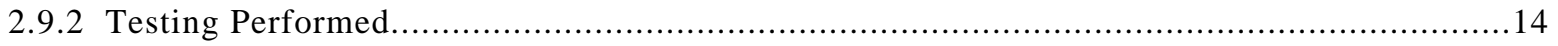

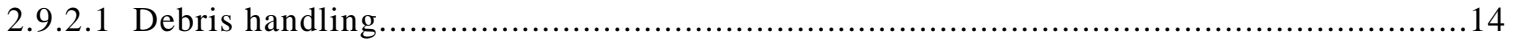

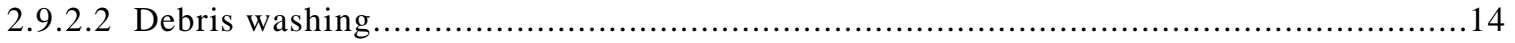

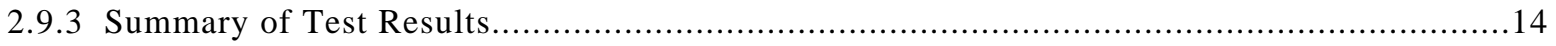

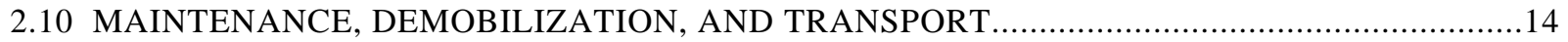

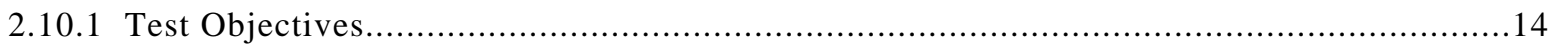

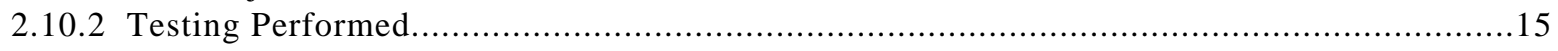

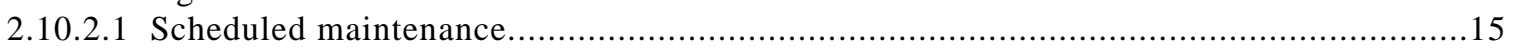

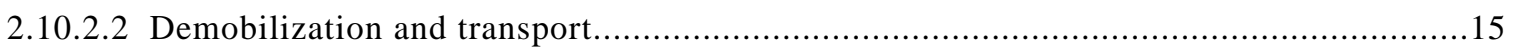

2.10.2.3 System integration and maneuverability in STF configuration........................................15

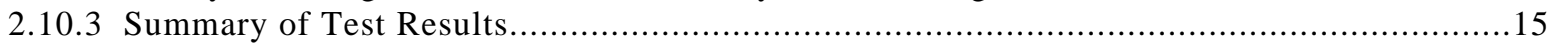

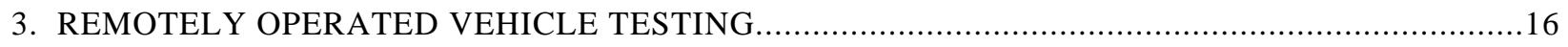

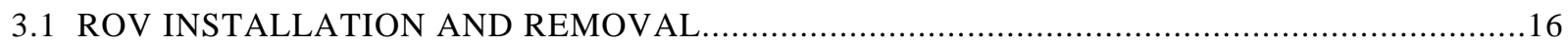

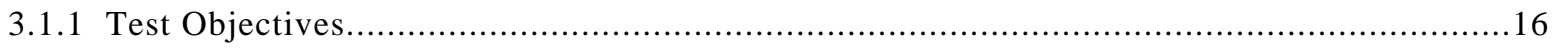

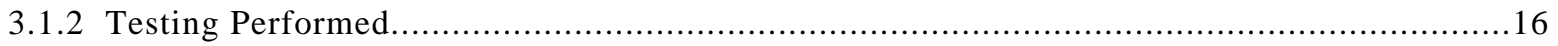

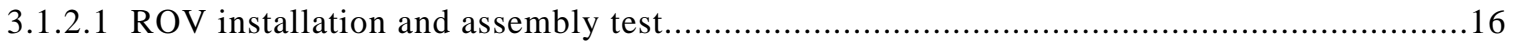

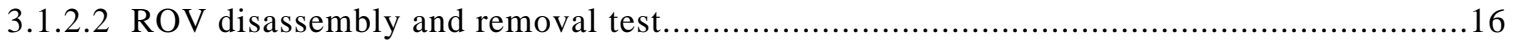

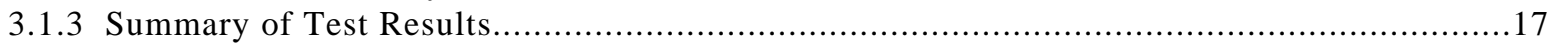

3.2 ROV DEPLOYMENT, RETRACTION, AND DECONTAMINATION ….....................................

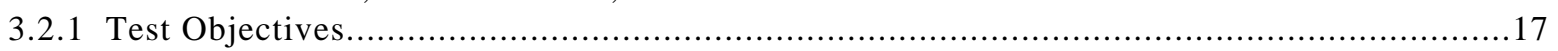

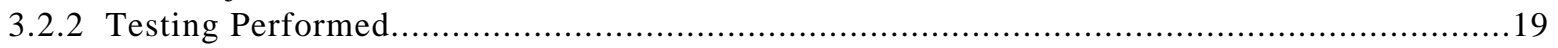

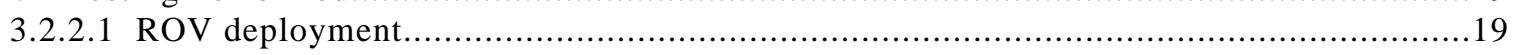

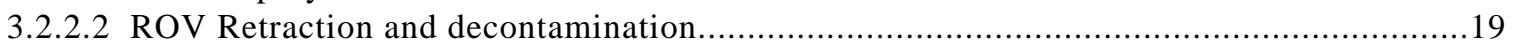

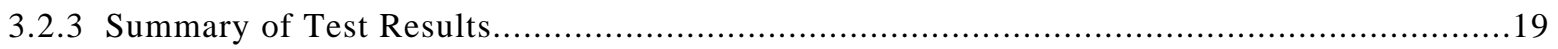

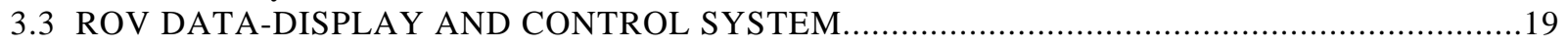

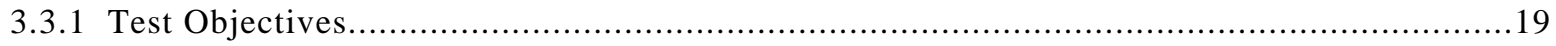

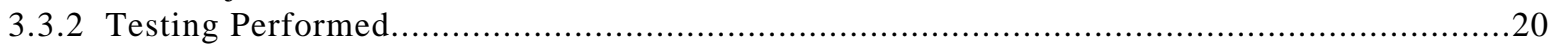

3.3.2.1 Data-display and control equipment (not listed in Testing Activities)..................................20

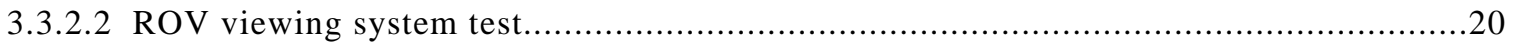

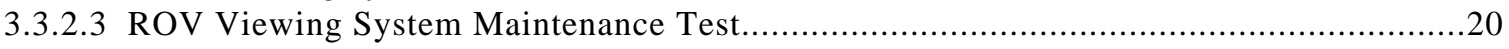

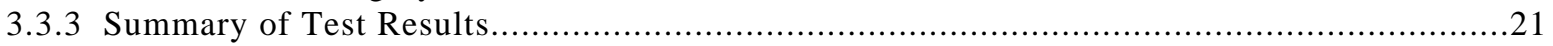

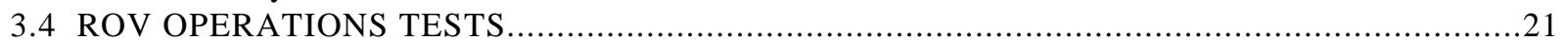

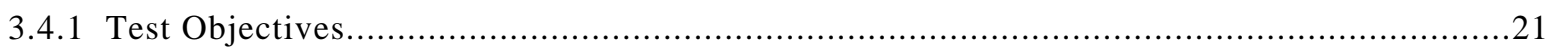

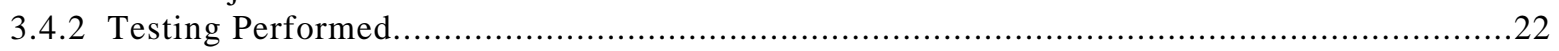




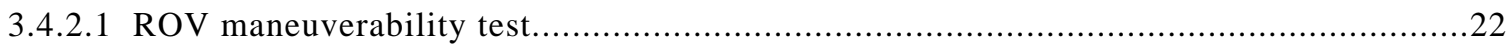

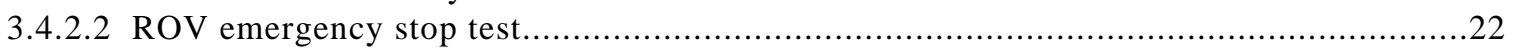

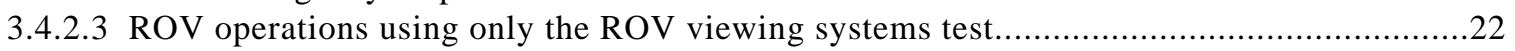

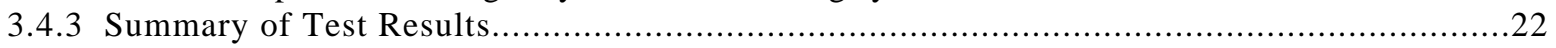

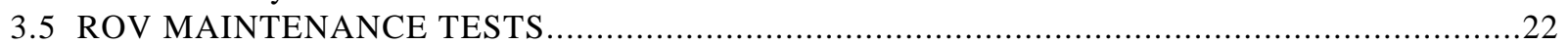

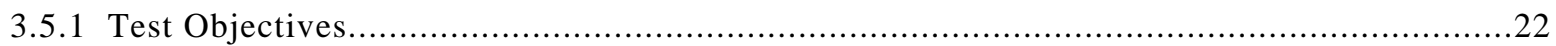

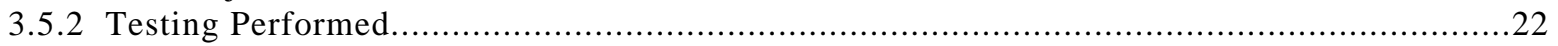

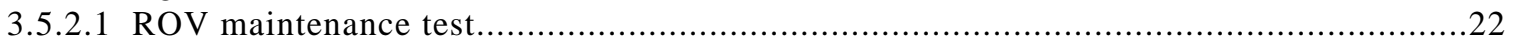

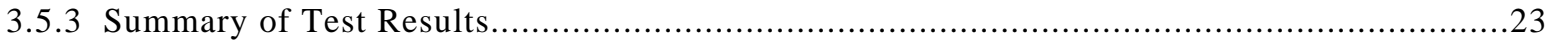

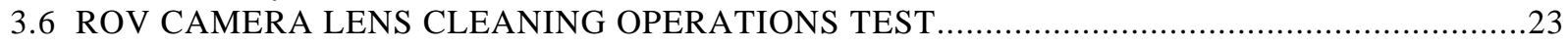

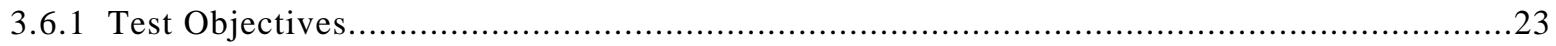

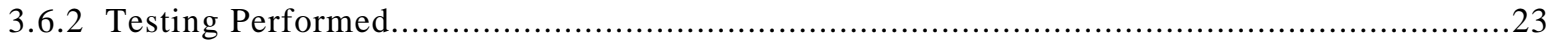

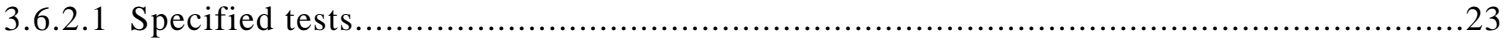

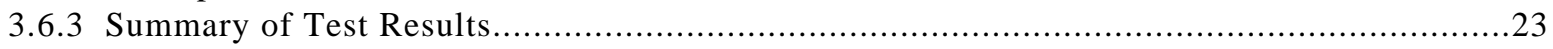

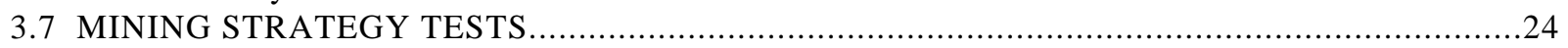

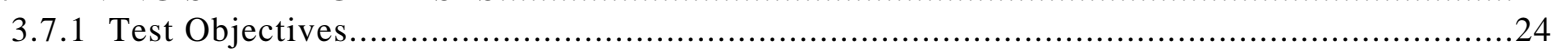

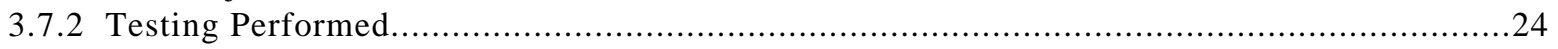

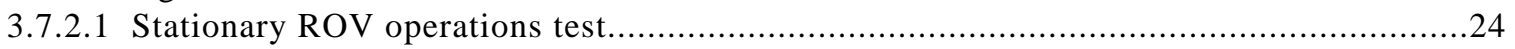

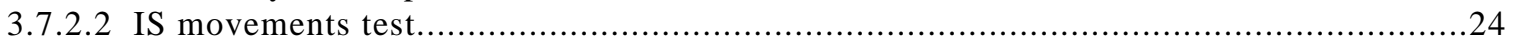

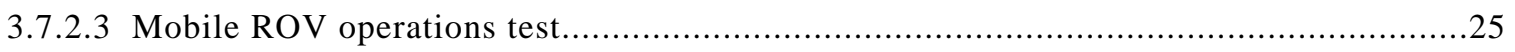

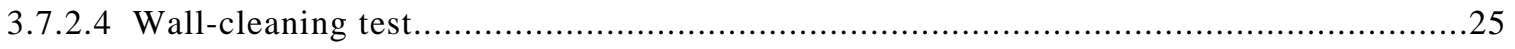

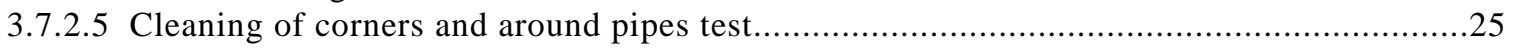

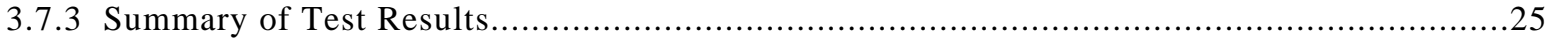

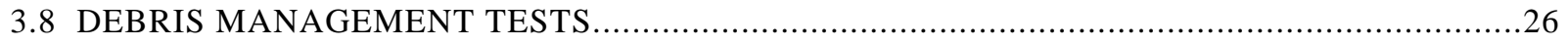

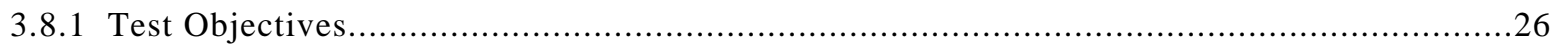

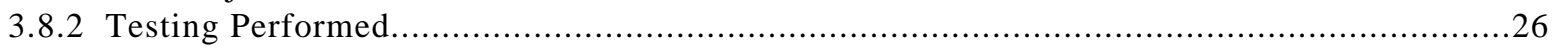

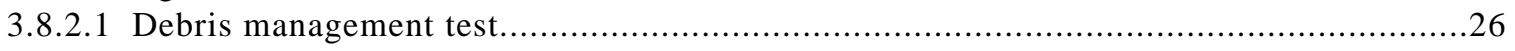

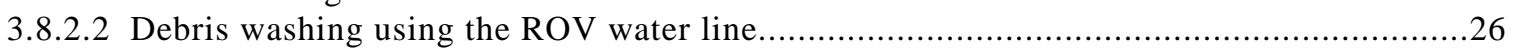

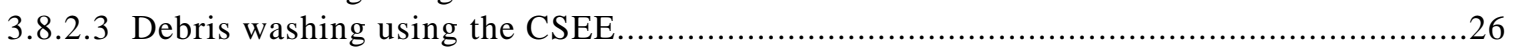

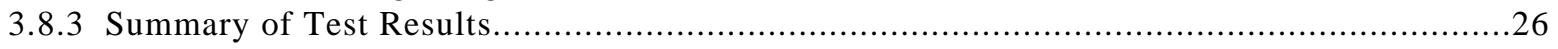

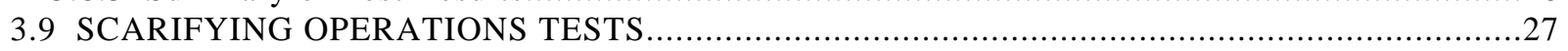

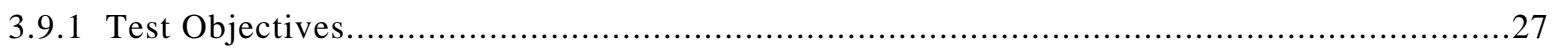

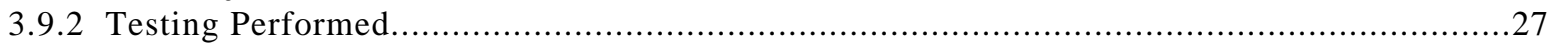

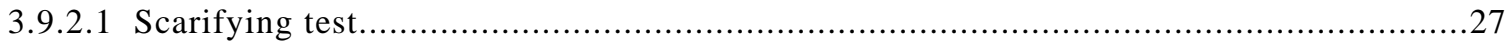

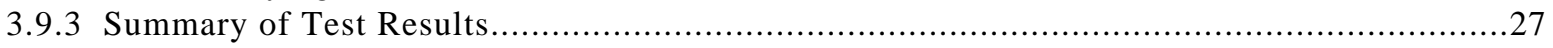

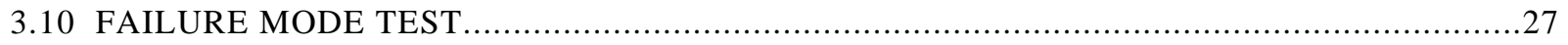

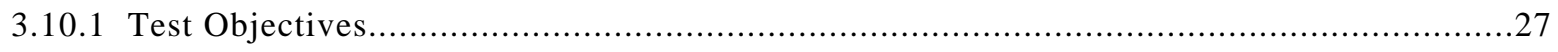

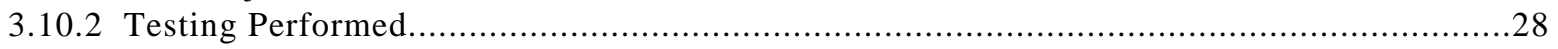

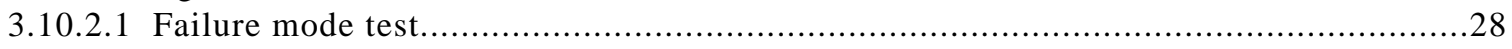

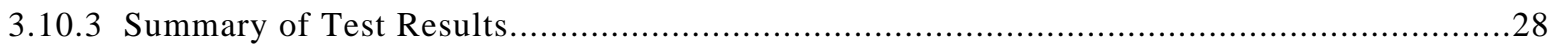

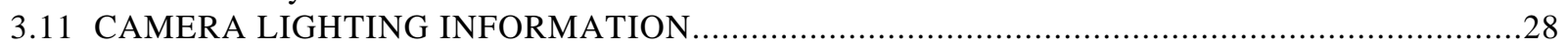

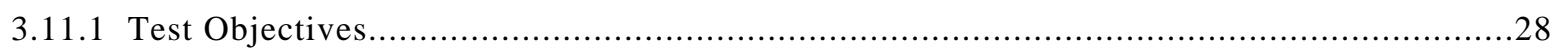

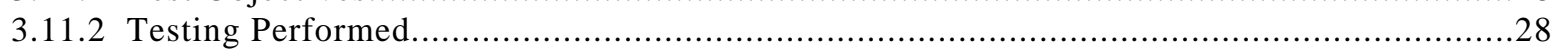

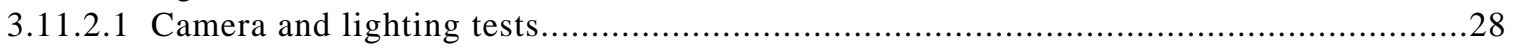

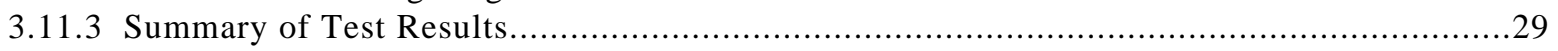

3.12 INTEGRATED SYSTEM (ROV, MLDUA, AND WD\&C) MINING TESTS ................................29

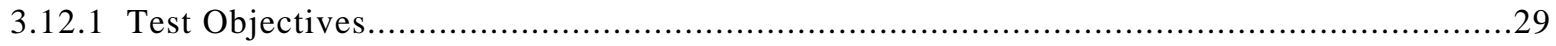

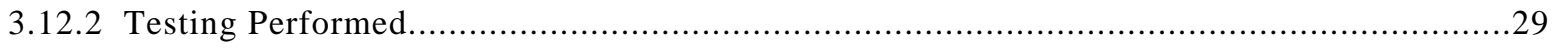

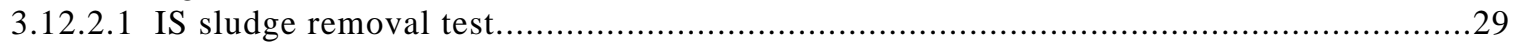

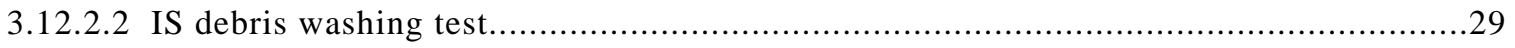

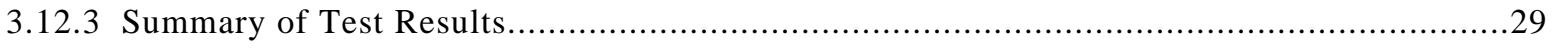

4. WASTE DISLODGING AND CONVEYANCE SYSTEM AND BALANCE OF PLANT EQUIPMENT

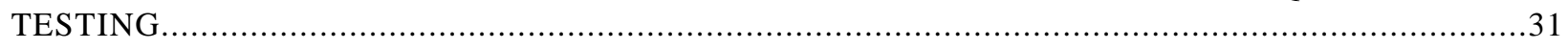

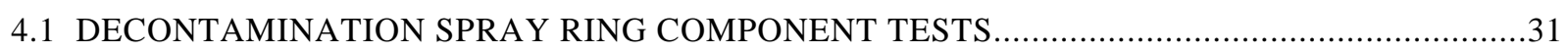




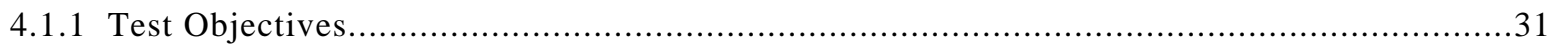

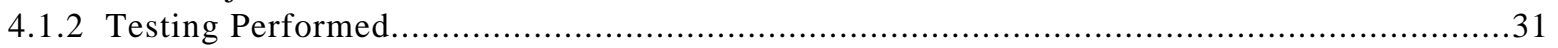

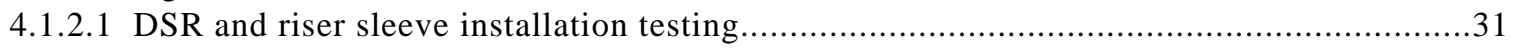

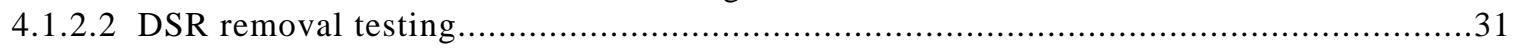

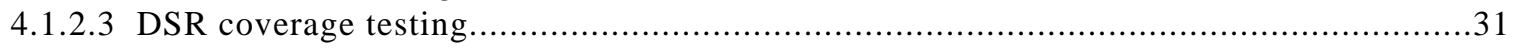

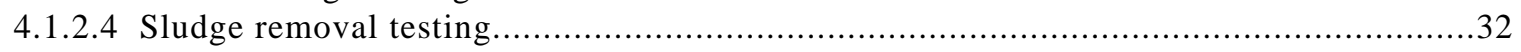

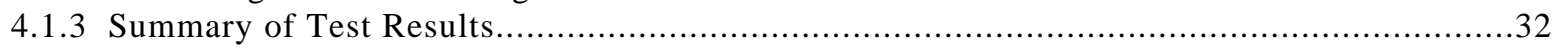

4.2 FLOW CONTROL EQUIPMENT AND CONTAINMENT BOX FUNCTIONAL TESTS.......................32

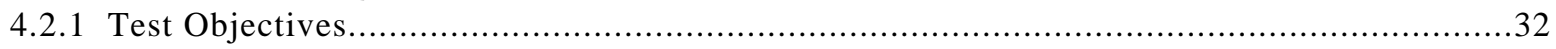

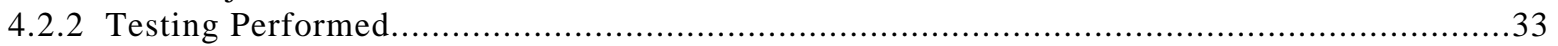

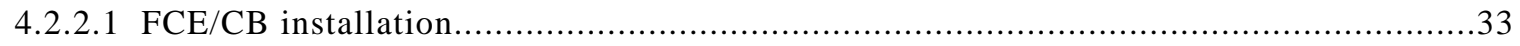

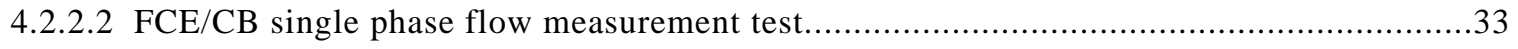

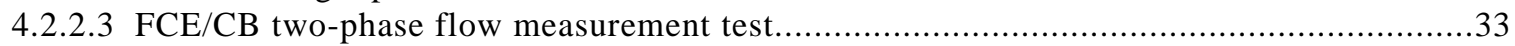

4.2.2.4 FCE/CB proportional sampler and valve operations test.................................................

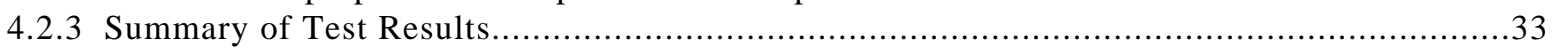

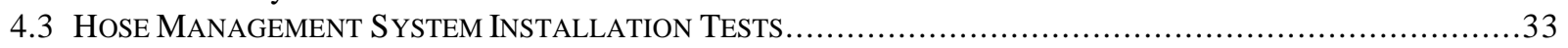

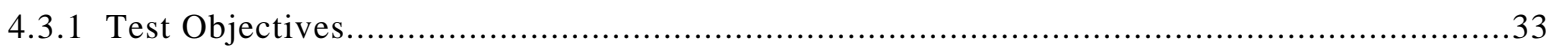

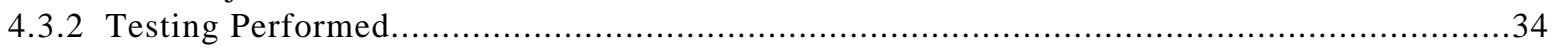

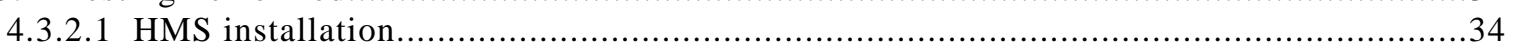

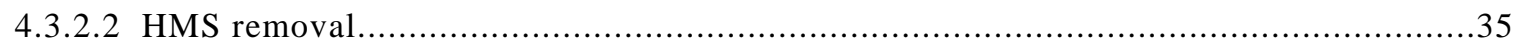

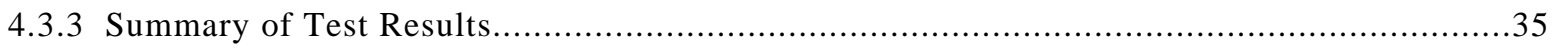

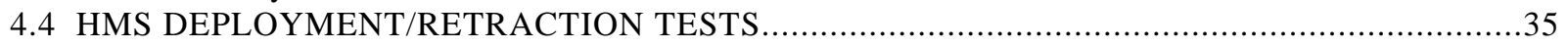

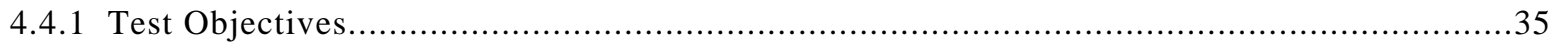

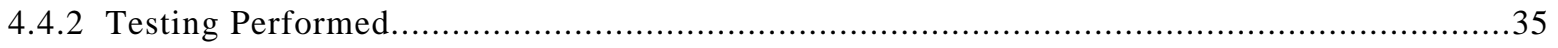

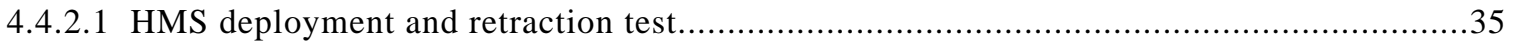

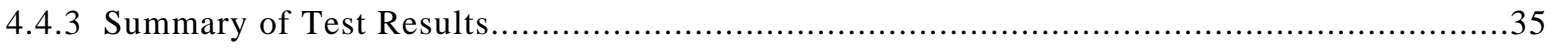

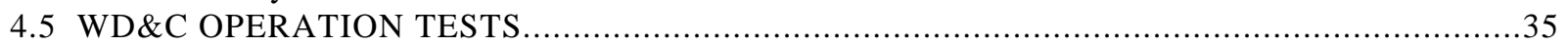

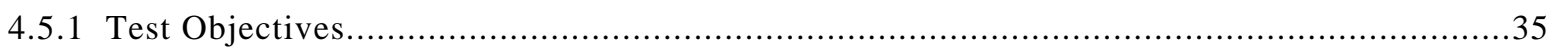

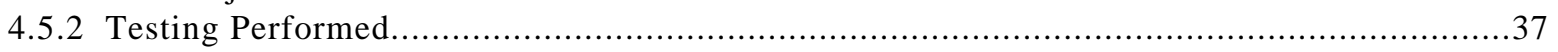

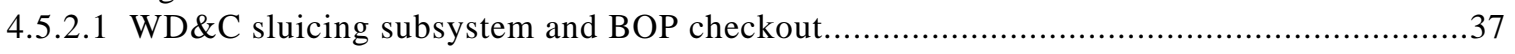

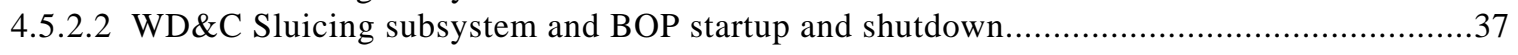

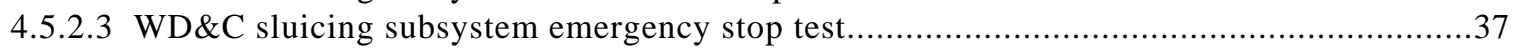

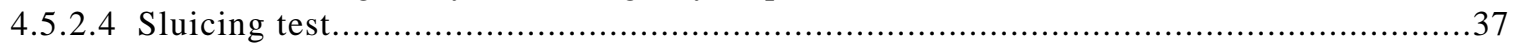

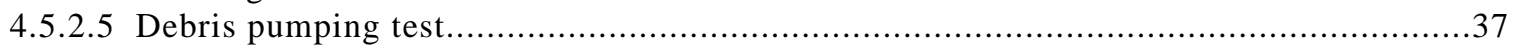

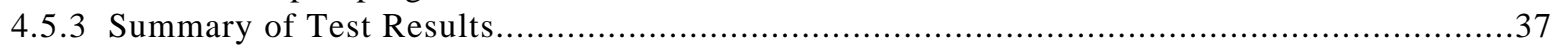

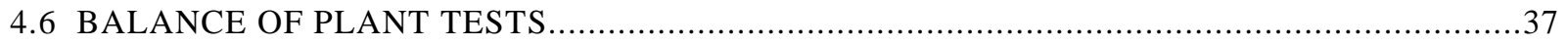

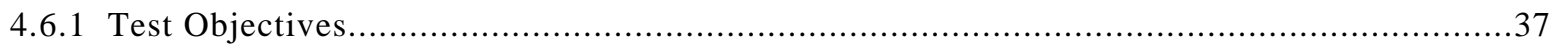

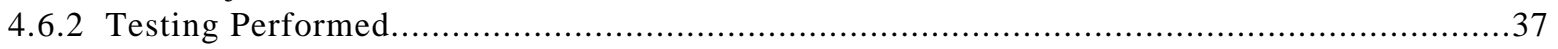

4.6.2.1 BOP equipment installation, checkout, and removal test............................................. 37

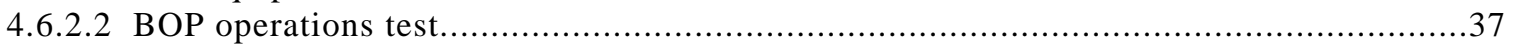

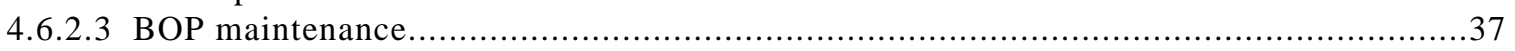

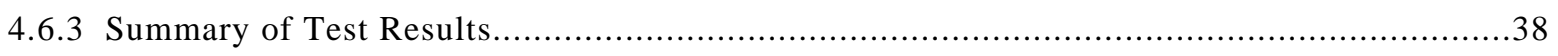

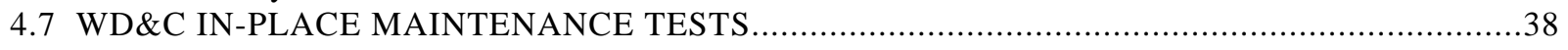

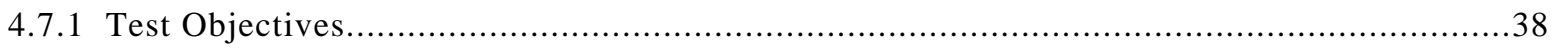

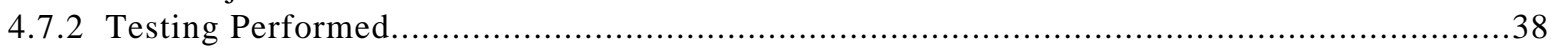

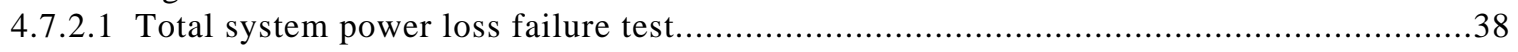

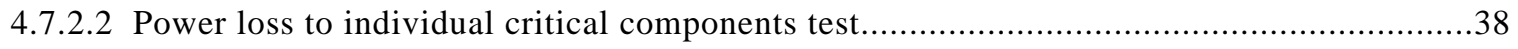

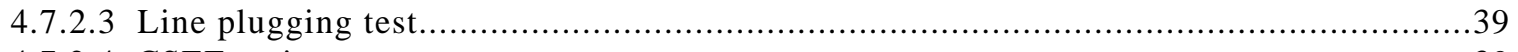

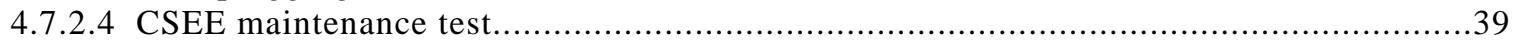

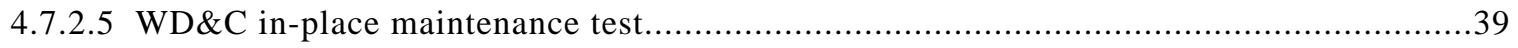

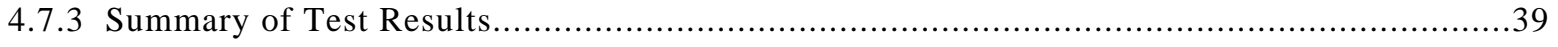

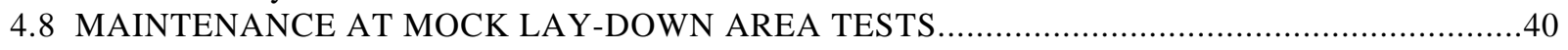

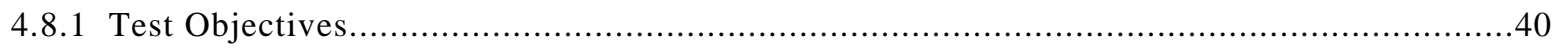

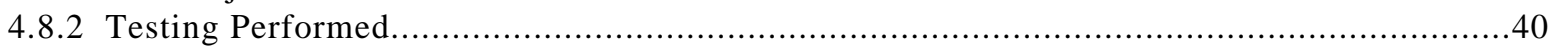

4.8.2.1 Swivel joint seal replacement and cable replacement test............................................... 40 


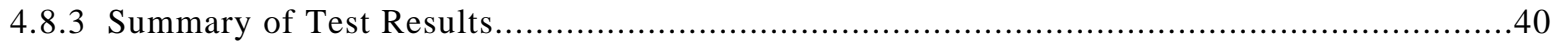

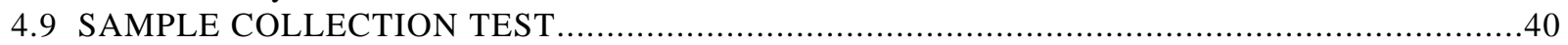

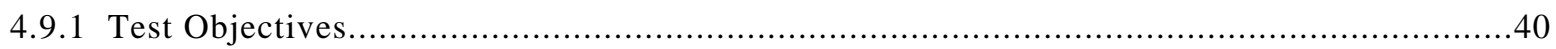

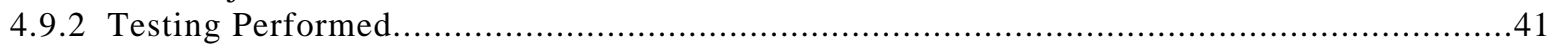

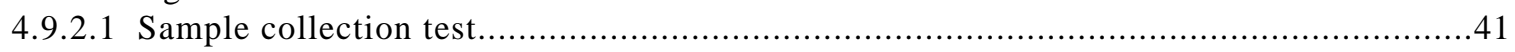

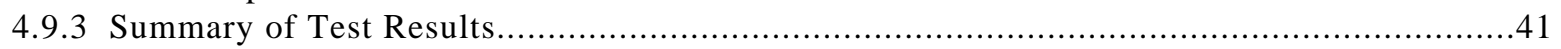

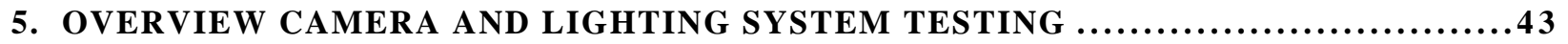

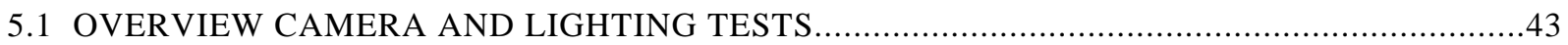

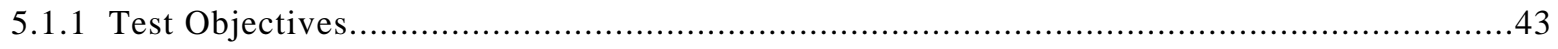

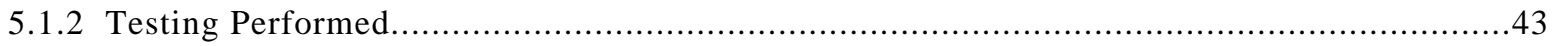

5.1.2.1 Camera and lighting equipment installation, checkout, and removal test...............................43

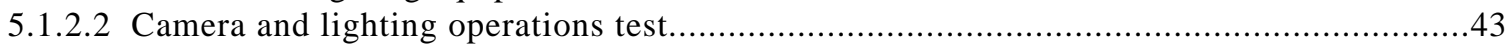

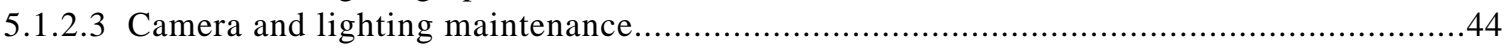

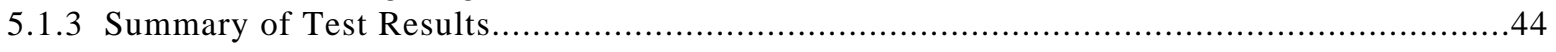

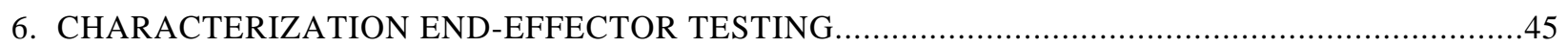

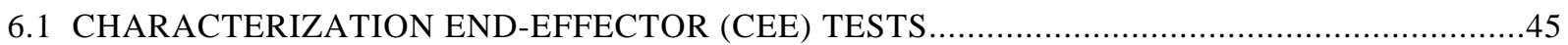

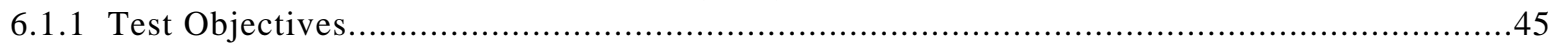

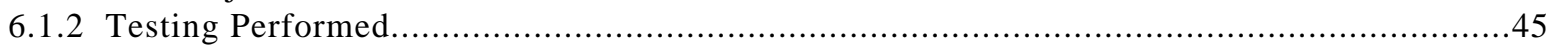

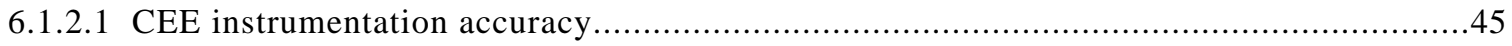

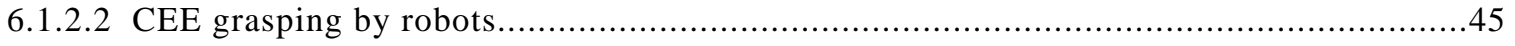

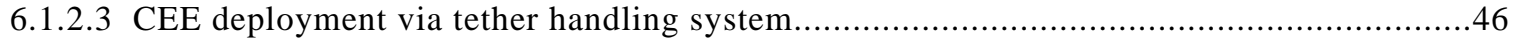

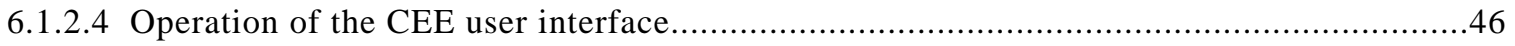

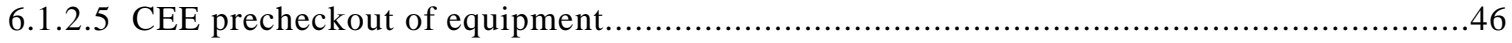

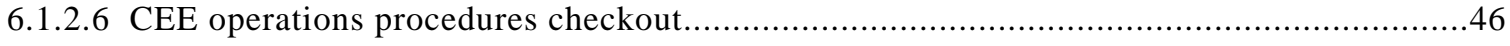

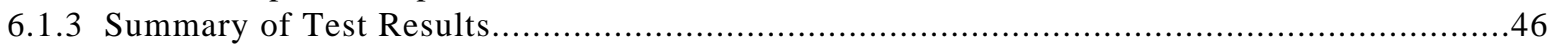

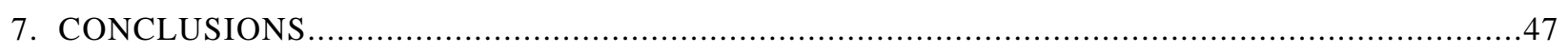

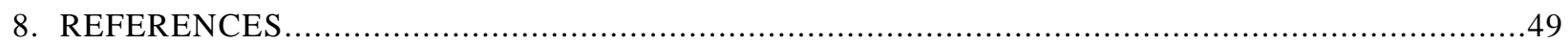




\section{LIST OF TABLES}

Table $\quad$ Page

Table 2.1.1 Installation and deployment test objectives..........................................................

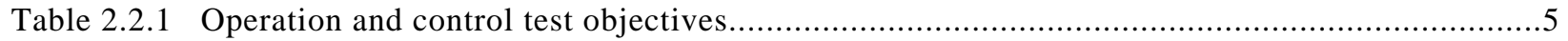

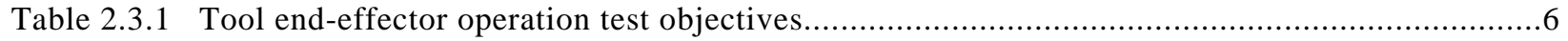

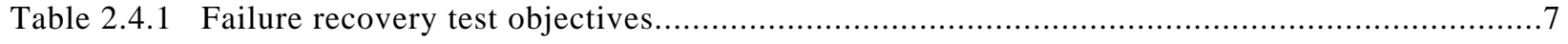

Table 2.5.1 Camera operation and control test objectives.....................................................

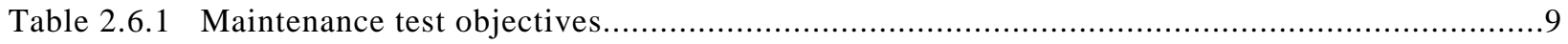

Table 2.7.1 Decontamination test objectives...................................................................... 10

Table 2.8.1 System integration and sludge test objectives..........................................................

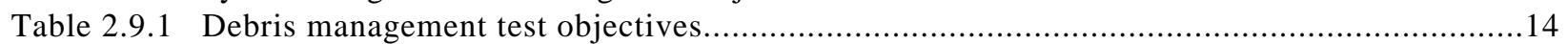

Table 2.10.1 Maintenance, demobilization, and transport test objectives............................................. 15

Table 3.1.1 ROV installation and removal test objectives......................................................16

Table 3.2.1 ROV deployment, retraction and decontamination test objectives.....................................18

Table 3.3.1 ROV data-display and control system test objectives..............................................20

Table 3.4.1 ROV operations test objectives..................................................................21

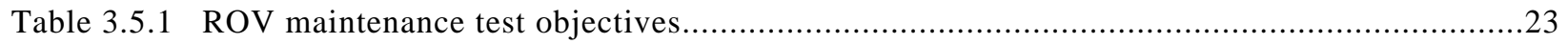

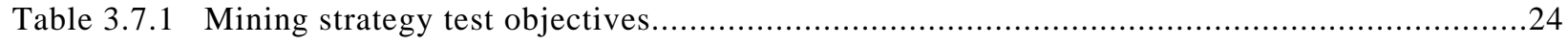

Table 3.8.1 Debris management test objectives.................................................................26

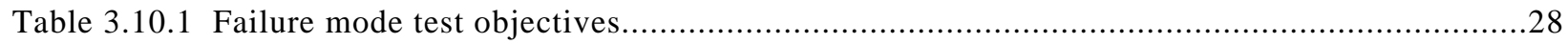

Table 3.12.1 Integrated system mining test objectives.......................................................29

Table 4.1.1 Decontamination spray ring component test objectives..................................................

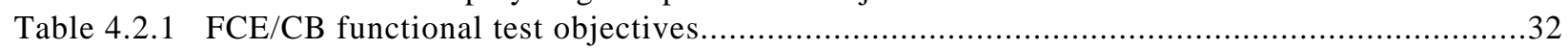

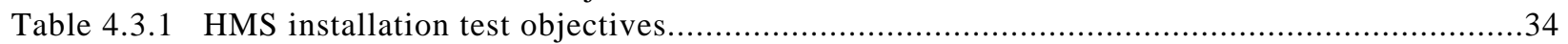

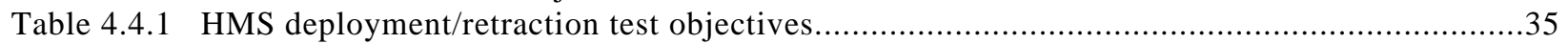

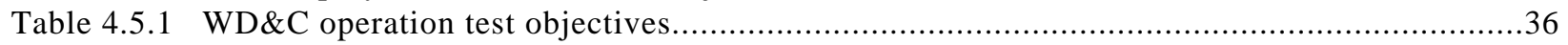

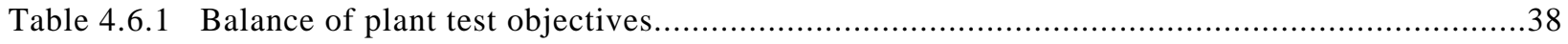

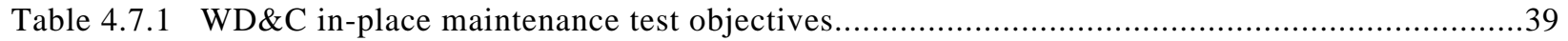

Table 4.8.1 Maintenance at mock lay-down area test objectives...................................................40

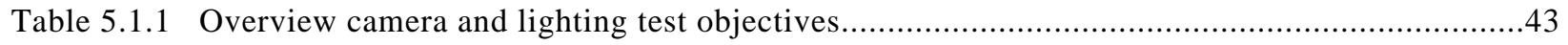

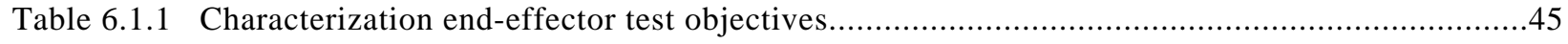




\section{ACRONYMS}

$\begin{array}{ll}\text { BOP } & \text { Balance of Plant } \\ \text { CEE } & \text { Character End-Effector } \\ \text { CERCLA } & \text { Comprehensive Environmental Response Compensation, and Liability Act } \\ \text { CSEE } & \text { Confined Sluicing End-Effector } \\ \text { DSR } & \text { Decontamination Spray Ring } \\ \text { FCE/CB } & \text { Flow Control Equipment and Containment Box } \\ \text { GAAT } & \text { Gunite and Associated Tanks } \\ \text { GEE } & \text { Gripper End-Effector } \\ \text { H\&R } & \text { Hoisting and Rigging } \\ \text { HMA } & \text { Hose Management Arm } \\ \text { HMS } & \text { Hose Management System } \\ \text { HPU } & \text { Hydraulic Power Unit } \\ \text { IS } & \text { Integrated System } \\ \text { MLDUA } & \text { Modified Light-Duty Utility Arm } \\ \text { NTF } & \text { North Tank Farm } \\ \text { ORNL } & \text { Oak Ridge National Laboratory } \\ \text { P\&E } & \text { Plant and Equipment } \\ \text { POR } & \text { Pont of Resolution } \\ \text { PPE } & \text { Personal Protective Equipment } \\ \text { ROV } & \text { Remotely Operated Vehicle } \\ \text { SPAR } & \text { Space Aerospace Limited } \\ \text { STF } & \text { South Tank Farm } \\ \text { THS } & \text { Tether Handling System } \\ \text { TIP } & \text { Tool Interface Plate } \\ \text { TIP } & \text { Tool Interface Plate } \\ \text { TRIC } & \text { Tank Riser Interface and Containment } \\ \text { TTCTF } & \text { Tanks Technology Cold Test Facility } \\ \text { VPM } & \text { Vertical Positioning Mast } \\ \text { WD\&C } & \text { Waste Dislodging and Conveyance } \\ & \end{array}$




\section{PREFACE}

This report provides a summary of the objectives, tests performed, and results of the testing of equipment to be used in the Gunite and Associated Tanks Treatability Study. The testing was performed from June 1996 to May 1997 at the Tanks Technology Cold Test Facility located at the 7600 complex at Oak Ridge National Laboratory. 


\begin{abstract}
This report provides a summary of the cold tests performed on the equipment to be used in the Gunite and Associated Tanks Treatability Study. The testing was performed from June 1996 to May 1997 at the Tanks Technology Cold Test Facility located at the 7600 complex at Oak Ridge National Laboratory. Testing of specific equipment grouped into the following sections: (1) Modified LightDuty Utility Arm Testing, (2) Remotely Operated Vehicle Testing, (3) Waste Dislodging and Conveyance System and Balance of Plant Equipment Testing, (4) Camera and Lighting System Testing, and (5) Characterization End-Effector Testing. Each section contains descriptions of a series of tests that summarize the test objectives, testing performed, and test results. General conclusions from the testing are also provided.
\end{abstract}




\section{INTRODUCTION}

The Oak Ridge National Laboratory (ORNL) Gunite and Associated Tanks (GAAT) are being remediated under the Comprehensive Environmental Response, Compensation, and Liability Act (CERCLA) process. A CERCLA treatability study is being conducted in the GAAT North Tank Farm prior to commencing remediation of the larger tanks in the South Tank Farm. ${ }^{1}$ A remotely operable tank, waste retrieval system has been developed for the GAAT remediation campaign. A summary description of this retrieval system is provided in Ref. 2 . To provide functional checkout of the system and operator training, a cold test program was implemented. The test program is described in Ref. 3.

In this report, test results are summarized. Testing was subdivided into: (1) evaluation of design alternatives, (2) acceptance tests, (3) functional tests, and (4) waste removal tests. The goals of the operational testing program were to: (1) demonstrate the technical feasibility of methods proposed for the removal of radiochemical sludge heels from the GAAT located at ORNL, (2) reduce the uncertainty in meeting the CERCLA requirements for the GAAT, and (3) minimize the overall costs to accomplish the first two objectives.

With the exception of several component tests, the test program was performed at the Tanks Technology Cold Test Facility (TTCTF) at the 7600 Complex at ORNL between June 1996 and May 1997. Detailed test plans were developed for each major system:

1. Modified Light-Duty Utility Arm (MLDUA) System, ${ }^{4}$

2. Remotely Operated Vehicle (ROV) System, ${ }^{5}$ and

3. Waste Dislodging and Conveyance (WD\&C) System. ${ }^{6}$

Each of these plans details a series of tests to be performed at the TTCTF on specific components and integration of components of the overall treatability study equipment. During the process of integrating the systems and conducting the tests outlined in Ref. 3, additional tests were identified to provide supplemental operations and maintenance data and training opportunities. Results of these supplemental tests, as well as a summary of lessons learned, are also included in this report. 
-2 - 


\section{MODIFIED LIGHT-DUTY UTILITY ARM TESTING}

Testing of the MLDUA System performance is delineated in Ref. 4. The testing performed is described in the following paragraphs.

\subsection{INSTALLATION AND DEPLOYMENT}

\subsubsection{Test Objectives}

MLDUA installation and deployment tests were performed to evaluate the equipment and procedures developed for lifting the MLDUA onto the tank platform, installing it into a tank, and positioning it for use. Before beginning these test activities, the system was configured in the same manner that it will be before installation in the North Tank Farm (NTF). ${ }^{4}$

These tests were conducted using the actual MLDUA equipment and the same personnel expected to be available for tank farm operations. The overall goals of these tests were to verify the accuracy and completeness of the installation and deployment procedures and to provide realistic training in their application. The following table presents the specific objectives of each test as listed in the test plan. ${ }^{4}$

Table 2.1.1 Installation and deployment test objectives

\begin{tabular}{ll}
\hline \multicolumn{1}{c}{ Test } & \multicolumn{1}{c}{ Objective } \\
\hline Hoisting and rigging test & $\begin{array}{l}\text { Demonstrate and verify hoisting and rigging procedures } \\
\text { Demonstrate any special tools required for hoisting and } \\
\text { rigging, and validate their operability }\end{array}$ \\
& $\begin{array}{l}\text { Document time required to perform hoisting and rigging } \\
\text { operations for estimation of the cost and the duration of } \\
\text { exposure to be incurred during tank farm operations }\end{array}$ \\
& $\begin{array}{l}\text { Perform mock hoisting and rigging scenarios to train } \\
\text { operators for each tank configuration }\end{array}$ \\
Tank deployment test & $\begin{array}{l}\text { Demonstrate, revise, and finalize written procedures for } \\
\text { positioning, checkout, and deployment of the MLDUA }\end{array}$ \\
& $\begin{array}{l}\text { Demonstrate any special tools required for tank deployment, } \\
\text { and validate their operability }\end{array}$ \\
& $\begin{array}{l}\text { Perform mock deployment scenarios to train operators for } \\
\text { each tank configuration }\end{array}$ \\
\hline
\end{tabular}

\subsubsection{Testing Performed}

2.1.2.1 Riser extension and Tank Riser Interface and Containment (TRIC) installation

The test procedure was followed and completed successfully.

\subsubsection{MLDUA installation}

The test procedure was followed and completed successfully. 


\subsubsection{MLDUA testing with pendant controller}

The test procedure was followed and completed successfully.

\subsubsection{Tank deployment and retraction Case 1}

The test procedure was followed and completed successfully.

\subsubsection{Tank deployment and retraction Case 2}

The test procedure was followed and completed successfully.

\subsubsection{Summary of Test Results}

During the course of the GAAT project, some test objectives were revised based on new knowledge and new circumstances. Hoisting and rigging was one of the areas where the objectives changed. Project management decided that it would be the responsibility of the ORNL Plant and Equipment (P\&E) Division Hoisting and Rigging (H\&R) group to perform the hoisting and rigging. Therefore, no hoisting and rigging procedures were written, and H\&R used their knowledge and skill to safely lift and set the equipment. Where appropriate, "critical lift plans" were used by H\&R.

No special tools were needed to lift the MLDUA; however, initially a lift fixture was designed and tried unsuccessfully to lift the MLDUA and its hydraulic power unit (HPU). The lifting fixture would have worked well with a uniform load; however, the HPU is not an evenly distributed load. H\&R determined that lifting slings of sufficient load-bearing capacity could be used in lieu of the lifting fixture. The MLDUA and HPU were successfully lifted and set in place using the slings.

The system lead and one qualified MLDUA operator observed the equipment installation and performed the necessary steps to connect the equipment following the MLDUA installation work instructions. One observation during installation was the need to fill around the feet of the riser extension to eliminate fall hazards. This change was added to the installation instructions for the move to the NTF.

Deployment and retraction of the vertical positioning mast (VPM) and MLDUA was performed numerous times. Each time some new aspect of operation was learned. This learning was documented in the form of procedure revisions, where steps were omitted or where improvements could be made to save time and money on the project. Secondary boot installation and removal was another area where improvements were made to the tools used in this operation. At the close of cold testing, two operators were fully qualified to perform MLDUA operations from the control console. Most of the project team members had been trained to assist the MLDUA operator with operations in the TRIC.

\subsection{OPERATION AND CONTROL}

\subsubsection{Test Objectives}

MLDUA operation and control tests were performed to evaluate the equipment and procedures developed for monitoring, operating, and controlling the MLDUA after it has been inserted into a tank. Before beginning these test activities, the system was configured in the same manner that it will be installed in the NTF. ${ }^{4}$

These tests were conducted using the actual MLDUA equipment and the same personnel who are expected to be available for tank farm operations. The overall goals of these tests were to verify the accuracy and completeness of the operation and control procedures and to provide realistic training in their application. The following table represents the specific objectives of each test as listed in the test plan. 
Table 2.2.1 Operation and control test objectives

\begin{tabular}{ll}
\hline \multicolumn{1}{c}{ Test } & \multicolumn{1}{c}{ Objective } \\
\hline Operational Controls & $\begin{array}{l}\text { Demonstrate, revise, and finalize written procedures for } \\
\text { training and operation of the MLDUA }\end{array}$ \\
Normal Operations & Determine the following with respect to the MLDUA: \\
& $\bullet$ capability to reach all areas of the floors and walls, \\
& - capauility to move and hold specified payloads in \\
required directions.
\end{tabular}

\subsubsection{Testing Performed}

\subsubsection{Normal operations: reach test}

The test procedure was modified and completed successfully. The test procedure required that several obstacles be erected in the TTCTF and that the MLDUA be required to maneuver around the obstacles. This requirement was deleted because no such obstacles are anticipated during GAAT operations.

\subsubsection{Normal operations: maneuverability tests}

The test procedure was modified and completed successfully. It was determined that the MLDUA would not be used for debris consolidation; therefore, the test requirement to maneuver with various pieces of debris was deleted. The test procedure also required that several obstacles be erected in the TTCTF and that the MLDUA be required to maneuver around the obstacles. This requirement was deleted.

\subsubsection{Normal operations: payload/maneuverability test}

The test procedure was modified and completed successfully. It was determined that the MLDUA would not be used for debris consolidation; therefore, the test requirement to maneuver with various pieces of debris was deleted. The test procedure also required that several obstacles be erected in the TTCTF and that the MLDUA be required to maneuver around the obstacles. This requirement was deleted.

\subsubsection{Summary of Test Results}

During the reach test, the arm was positioned straight out at a known height off the floor of 37 in. The VPM position was -334.3 in. The VPM was raised until the "tank riser conflict alarm" was triggered at $-235.5 \mathrm{in.}$ The robot arm shoulder pitch joint had a range of $100 \mathrm{in}$. in the test pit. Also, the wrist pitch was placed at $+90^{\circ}$ to inspect the tank ceiling. From the reach test, it was determined that the MLDUA could reach most areas (not blocked by equipment) in the tank.

During the maneuverability testing it was learned that joint level control is the smoothest and the most precise motion control of the MLDUA system. The operator may select either the manual or auto sequence mode of control when operating. In the manual mode, the operator controls one joint at a time, which is the slowest motion control. In auto sequence mode, the computer drives all joints at once, as programmed by the operator. 
Point of resolution (POR) control drives the robot arm tool interface plate (TIP) to a specified X, Y, Z, pitch, yaw, roll location inside the tank. This motion is not always the smoothest because the robot arm can have vibrations, especially at the higher POR speeds. The operator may select either the manual or auto sequence mode of operation. The manual mode was used much more than the auto sequences mode because of operator preferences. In manual mode, the operator "flies" the gripper end effector (GEE), which is attached to the TIP using the two joysticks. A modification was made to increase the joystick update data rate, which resulted in smoother control while in the manual POR mode.

\subsection{TOOL END-EFFECTOR OPERATION}

\subsubsection{Test Objectives}

The MLDUA end-effector operation tests were performed to evaluate the equipment and procedures developed for operation of end effectors attached to the MLDUA. Before beginning these test activities, the system was configured in the same manner that it will be installed in the NTF. ${ }^{4}$

These tests were conducted using the actual MLDUA equipment and the same personnel who are expected to be available for tank farm operations. The overall goals of these tests were to verify the accuracy and completeness of the end-effector operations procedures and to provide realistic training in their application. The following table presents the specific objectives of each test as listed in the test plan.

Table 2.3.1 Tool end-effector operation test objectives

Test

Objective

End-effector deployment change

End-effector operations
Demonstrate and revise procedures for changing end effectors to safely accomplish these activities with as low as reasonably achievable exposures

Demonstrate and revise procedures, and verify operations of characterization end effector

\subsubsection{Testing Performed}

\subsubsection{Characterization end effector (CEE) changeout and operations}

The test procedure was modified and completed successfully. The CEE drilling tool failed to meet requirements and was removed from the system.

\subsubsection{Rake end-effector changeout and operations}

This test was deleted based on the decision to not continue with rake design.

\subsubsection{Basket end-effector changeout and operations}

This test was revised to be an ROV test. The debris consolidation function was assigned solely to the ROV.

\subsubsection{Summary of Test Results}

Handling of the CEE inside the TRIC required two operators to position the CEE for the GEE to acquire. This proved to be a difficult task that was further complicated by the CEE umbilical being stiff and difficult to handle.

$$
-6-
$$


During the deployment and retraction of the MLDUA and CEE, the CEE umbilical had to be physically handled through the glove ports to maintain tension on the tether handling system (THS) cable reel while not allowing the umbilical to deliver any load to the MLDUA; this also proved to be difficult. The entire operation of this task also exposes the operator handling the umbilical to the radiation shine through the riser. Redesign of the CEE sensor head and tether is recommended to simplify cable management issues. This may not be practical until after NTF operations when further lessons learned will be available.

\subsection{FAILURE RECOVERY}

\subsubsection{Test Objectives}

The MLDUA failure recovery tests were performed to evaluate the procedures developed for offnormal operations of the MLDUA. Before beginning these test activities, the system was configured in the same manner that it will be after installation in the NTF. ${ }^{4}$

These tests were conducted using the actual MLDUA equipment and the same personnel who are expected to be available for tank farm operations. The overall goals of these tests were to verify the accuracy and completeness of the failure recovery procedures and to provide training in their application. The following table presents the specific objectives of the test as listed in the tests plan. ${ }^{4}$

Table 2.4.1 Failure recovery test objectives

Test $\quad$ Objective

Failure recovery

Demonstrate, verify (as defined in the specifications), revise, and finalize procedures for recovery from failures for each MLDUA system arrangement. These failures may include the following:

- power loss,

- E-kill,

- computer communication loss,

- joint failure, and

- camera failure.

\subsubsection{Testing Performed}

\subsubsection{Electrical-power-loss recovery test}

This test was performed as part of the final acceptance testing performed by Spar Aerospace Limited (SPAR).

\subsubsection{Computer communication system failure}

This test was performed as part of the final acceptance testing performed by SPAR and witnessed by ORNL staff.

\subsubsection{Recovery from emergency soft stop}

This test was performed as part of the final acceptance testing performed by SPAR and witnessed by ORNL staff. 


\subsubsection{Joint failure}

This test was performed as part of the final acceptance testing performed by SPAR and witnessed by ORNL staff.

\subsubsection{Camera failure}

This test was deleted because the system will not be operated in the condition described in the test with no overview cameras. Multiple cameras will be available at the GAAT.

\subsubsection{Summary of Test Results}

During the acceptance tests it was demonstrated that the MLDUA could safely recover from the most likely failure events such as electrical power loss, computer communication error, activation of an emergency stop switch, and joint limit failures.

\subsection{CAMERA OPERATION AND CONTROL}

\subsubsection{Test Objectives}

The MLDUA camera operation and control tests were performed to evaluate the procedures developed for off-normal operations of the MLDUA. Before beginning these test activities, the system was configured in the same manner that it will be installed in the NTF. ${ }^{4}$

These tests were conducted using the actual MLDUA equipment and the same personnel who are expected to be available for tank farm operations. The overall goals of these tests were to verify the accuracy and completeness of the camera operation and control procedures and to provide realistic training in their application. The following table presents the specific objectives of each test as listed in the test plan. ${ }^{4}$

Table 2.5.1 Camera operation and control test objectives

Test

Objective

Camera operations

Verify that the camera and lighting system operate properly after installation on the MLDUA. Information obtained shall include:

- field of vision,

- focus,

- lighting design and placement, and

- lens cleaning requirements.

\subsubsection{Testing Performed}

\subsubsection{Field of vision and focus}

This test was performed as a matter of course during other operations.

\subsubsection{Lighting design and placement}

This test was performed as a matter of course during other operations. 


\subsubsection{Summary of Test Results}

These tests were performed as a matter of course during the other MLDUA testing; that is, as the testing was conducted the MLDUA cameras were used to direct the operator during operations. It was determined by project staff that the cameras that were installed were adequate for operations and that no further data would be required.

\subsection{MAINTENANCE}

\subsubsection{Test Objectives}

The MLDUA maintenance tests were performed to evaluate the procedures and methods developed for routine and off-normal maintenance and decontamination activities for the MLDUA. Before beginning these test activities, the system was configured in the same manner that it will be installed in the NTF.

These tests were conducted using the actual MLDUA equipment and the same personnel who are expected to be available for tank farm operations. The overall goals of these tests were to verify the practicality and completeness of the maintenance procedures and to provide realistic training in their application. The following table presents the specific objectives of each test as listed in the test plan. ${ }^{4}$

Table 2.6.1 Maintenance test objectives

Test Objective

MLDUA maintenance

Perform routine maintenance, and demonstrate and revise written procedures for maintenance of the systems included in the MLDUA

Perform mock maintenance scenarios for training in maintenance procedures, including boot replacement and camera replacement

Document the time required to demonstrate maintenance actions and to estimate cost and exposures for tank farm operations

\subsubsection{Testing Performed}

\subsubsection{Camera and light maintenance}

The test procedure was modified and completed successfully. Maintenance was performed in the test pit rather than the robot arm being retracted into the TRIC to perform the maintenance.

\subsubsection{Boot replacement}

The test procedure was followed and completed successfully.

\subsubsection{Unexpected MLDUA maintenance}

One significant repair was performed during cold testing. The locking tabs on the VPM rotation axis were not properly engaged. This problem required partial dismantlement of the axis support. After this repair no further problems were encountered.

$$
-9 \text { - }
$$




\subsubsection{Summary of Test Results}

A tool was developed to facilitate primary boot replacement when attached to a tank riser. The procedure for primary boot replacement was a valuable exercise because preventing contamination of the MLDUA interior is extremely important. The cold tests offered an opportunity to define tool requirements and practice contamination control procedures as well as the test tasks.

\subsection{DECONTAMINATION}

\subsubsection{Test Objectives}

The MLDUA decontamination test was performed to evaluate the equipment and procedures developed for decontaminating the MLDUA and ancillary systems. ${ }^{4}$

These tests were conducted using the actual MLDUA equipment and the same personnel who are expected to be available for tank farm operations. The overall goals of these tests were to verify the practicality and completeness of the MLDUA procedures and to provide realistic training in their application. The following table represents the specific objectives of each test as listed in the test plan. ${ }^{4}$

Table 2.7.1 Decontamination test objectives

Test $\quad$ Objective

Decontamination Demonstrate decontamination-spray-ring effectiveness

Document the volume of water used in decontaminationspray-ring and spray-wand decontamination events and the number of decontamination events

\subsubsection{Testing Performed}

\subsubsection{Decontamination}

The test procedure was followed and completed successfully.

\subsubsection{Summary of Test Results}

This test was performed several times in an attempt to determine the most effective means of decontaminating the MLDUA. The most effective means was determined to be at an operating pressure of 500 psig and using the hand-held spray wand in the TRIC to remove any remaining sludge.

The decontamination spray ring (DSR) operations proved to be a very violent operation to the robot arm, secondary boot, and TRIC. The most effective pressure for the DSR was determined by the amount of decontamination water that was directed back into the TRIC and the effectiveness of the spray at removing sludge from the secondary boot. It was found that 500 psig effectively removed all the wet sludge on the boot except the sludge that had dried onto the boot and the sludge that had been caught in the folds of the boot. No change was noticeable in sludge removal up to $1500 \mathrm{psig}$ DSR pressure. At pressures above 500 psig, the MLDUA was prone to positioning errors caused by deflection of the VPM by the jet stream. It was decided to administratively restrict DSR operations for the MLDUA to 500 psig and below. 


\subsection{SYSTEM INTEGRATION AND SLUDGE REMOVAL}

\subsubsection{Test Objectives}

The Integrated System (IS) performance tests were performed to evaluate the equipment and procedures developed for connecting the MLDUA and WD\&C systems and for operating them in concert. Before beginning these test activities, the system was configured in the same manner that it will be installed in the NTF. The IS performance testing sequence was completed in the NTF configuration (riser spacing of approximately $10 \mathrm{ft}$. on center). The IS was then redeployed in the

South Tank Farm (STF) configuration (riser spacing of approximately $20 \mathrm{ft}$. on center), and operational testing activities were repeated. ${ }^{4}$

These tests were conducted using the actual IS equipment and the same personnel who are expected to be available for tank farm operations. The overall goals of these tests were to verify the accuracy and completeness of the IS sludge removal procedures and to provide realistic training in their application. The following table presents the specific objectives of each test as listed in the test plan. ${ }^{4}$

\subsubsection{Testing Performed}

\subsubsection{System integration and maneuverability}

The test procedure was followed and completed successfully.

\subsubsection{Sludge transfer}

The test procedure was followed and completed successfully.

\subsubsection{Gunite scarification}

The test procedure was followed and completed successfully.

\subsubsection{Corner cleaning}

The test procedure was followed and completed successfully.

\subsubsection{Summary of Test Results}

During the grasping of the confined sluicing end-effector (CSEE) X-handle, the CSEE did not move around as was expected. This was because the hose management arm (HMA) hoses provided sufficient stiffness to hold the CSEE in position during the maneuver. Particular attention was needed to release the CSEE in a position directly below the HMA that would avoid causing the CSEE to swing and damage the MLDUA.

The maximum VPM rate for sluicing operations was determined to be $0.25 \mathrm{in} . / \mathrm{second}$. This VPM rate would allow the robot arm to move quickly across the tank floor, but would still allow the operator fine control of the height of the CSEE above the floor. It was also learned that the robot arm works fine in POR mode for small areas; however, for larger areas the joint rate of control was preferred to reduce the robot arm-following control system warnings and errors.

For the sludge transfer testing the operator initially positioned the CSEE in an area that needed to have simulated sludge removed. After the sluicing system was started, the CSEE was lowered into the sludge to the desired depth and within the limits of the HMA. It was also observed during this testing that the efficiency of sludge removal increased as the operator gained experience in the mining operation.

The Gunite scarification test was performed using a painted area of the wall in the test pit.

Positioning the CSEE at a place on the wall also performed this test, and once the cutting system was 
started the VPM was moved vertically to cause a single vertical swath to be cleaned. It was observed during this testing that the efficiency of wall cleaning increased as the operator gained experience in the operation.

To clean around corners and pipes, the CSEE was positioned at least $1 \mathrm{ft}$. away (beyond the point of convergence of the cutting jets) to provide a broad burst of water for washing away the sludge. The only area that proved to be challenging for cleaning was the corner of the test pit. However, because there are no corners in the GAAT tanks, this is not a significant finding. 
Table 2.8.1 System integration and sludge test objectives

Tests

Objectives

System integration

Movement

Sludge transfer

Gunite cleaning/removal
Verify procedures for integration of the MLDUA and WD\&C tests

Verify IS range of motion, and perform checkout of the IS with both passive hose management system (HMS) and an interactive joint-driven HMS to determine which mode of operation is preferred

Monitor and record the effects on the MLDUA when the CSEE is dragged across the tank floor

Demonstrate HMS arm movement capabilities after the arm is positioned at an inclination off-normal to the tank floor surface

Confirm solids removal efficiencies for selected mining strategies using simulated (inert) sludge of varying densities. Parameters to be monitored during sludge transfer include:

- jet pump motive fluid pressure,

- cutting jet water pressure,

- CSEE standoff distance,

- CSEE linear speed,

- supernate removal rate,

- number of operators required for IS operation,

- balance of plant coordination requirements,

- human factors affecting operator duty cycle,

- personal protective equipment requirements,

- equipment duty cycles,

- time between equipment failures, and

- time spent working on potentially "hot" equipment.

Demonstrate equipment-tracking scenarios using developed mining strategies for full tank coverage

Document residual sludge left in tank following each mining strategy test

Document the following approximate solids concentrations throughout mining activities:

- per unit of operating time,

- per unit of water added at jet pump, and

- per unit of water added at the CSEE.

Determine Gunite ${ }^{\mathrm{TM}}$ cleaning/scarifying efficiencies using established cleaning/scarifying pressures 


\subsection{DEBRIS MANAGEMENT}

\subsubsection{Test Objectives}

The IS debris management tests were performed to evaluate the equipment and procedures developed for removing debris from the tanks using the IS. Before beginning these test activities, the system was configured in the same manner that it will be installed in the NTF.

These tests were conducted using the actual IS equipment and the same personnel who are expected to be available for tank farm operations. The overall goals of these tests were to verify the accuracy and completeness of the IS debris management procedures and to provide realistic training in their application. The following table presents the specific objectives of each test as listed in the test plan. ${ }^{4}$

Table 2.9.1 Debris management test objectives

Test Objective

Debris handling

Demonstrate arm movements required and force/torque effects when using the MLDUA to handle debris

Demonstrate removal techniques for debris that is capable of being pumped, and document the efficiencies. Record force/torque effects from these operations

Debris washing

Demonstrate methods to wash debris

\subsubsection{Testing Performed}

\subsubsection{Debris handling}

This test was deleted based on the decision that the debris consolidation function was assigned solely to the ROV. Replacement tongs for the GEE would be required but have not yet been designed.

\subsubsection{Debris washing}

This test was deleted based on the decision that the debris consolidation function was assigned solely to the ROV. Replacement tongs for the GEE would be required but have not yet been designed.

\subsubsection{Summary of Test Results}

This test was deleted based on the decision that the debris consolidation function was assigned solely to the ROV. Replacement tongs for the GEE would be required but have not yet been designed.

\subsection{MAINTENANCE, DEMOBILIZATION, AND TRANSPORT}

\subsubsection{Test Objectives}

The IS maintenance, demobilization, and transport test was performed to evaluate the procedures developed for demobilization and transport of the IS. Before beginning these test activities, the IS was configured in the same manner that it will be installed in the NTF. ${ }^{4}$

These tests were conducted using the actual IS equipment and the same personnel who are expected to be available for tank farm operations. The overall goals of these tests were to verify the accuracy 
and completeness of the IS maintenance procedures and to provide realistic training in their application. The following table presents the specific objectives of each test as listed in the test plan. ${ }^{4}$

Table 2.10.1 Maintenance, demobilization, and transport test objectives

Test

Objective

IS Maintenance,

demobilization, and transport

Demonstrate procedures for demobilization and transportation of the MLDUA and WD\&C systems

\subsubsection{Testing Performed}

\subsubsection{Scheduled maintenance}

The test procedure was followed and completed successfully.

\subsubsection{Demobilization and transport}

The test procedure was followed and completed successfully.

2.10.2.3 System integration and maneuverability in STF configuration

The test procedure was followed and completed successfully.

\subsubsection{Summary of Test Results}

The MLDUA System was moved from the NTF configuration to the STF configuration. This provided a chance to practice the mobilization process. No surprises were encountered during this activity. The WD\&C System was removed from the TTCTF platform on several occasions to repair problems with the guide bars for the mast. This provided opportunities to evaluate both a one-piece demobilization and a two-piece demobilization (separating the mast storage tube from the containment structure). 


\section{REMOTELY OPERATED VEHICLE TESTING}

Performance testing of the Houdini ROV and IS performance testing is delineated in Ref. 5. The testing performed is described in the following paragraphs.

\subsection{ROV INSTALLATION AND REMOVAL}

\subsubsection{Test Objectives}

ROV installation and removal tests were performed to verify the accuracy and completeness of the ROV installation and removal procedures and to establish baseline times for completing the activities and potential personnel exposures. ${ }^{5}$

ROV installation and removal testing was performed at the ORNL TTCTF when the ROV arrived on site. The testing was performed to verify that all components of the ROV were present and that the ROV could be installed onto a tank as required. ${ }^{5}$

The Tether Management and Deployment System (TMADS) transport installation and removal tests demonstrated (1) the hoisting and rigging requirements to position the TMADS on the platform, (2) the installation procedures for connecting the TMADS and confinement structure to the tank riser, (3) ROV checkout procedures, and (4) ROV removal procedures. These tests were performed on site as part of the actual transport and installation of equipment to the TTCTF. The test objectives are listed in Table 3.1.1.

\subsubsection{Testing Performed}

\subsubsection{ROV installation and assembly test}

The test procedure was followed and completed successfully.

\subsubsection{ROV disassembly and removal test}

The test procedure was followed and completed successfully.

Table 3.1.1 ROV installation and removal test objectives

Test

Installation and removal
Demonstrate and verify the hoisting and rigging equipment and procedures

Demonstrate the installation, connection, checkout, and removal requirements and procedures

Demonstrate any special tools required, and validate their operability

Revise and finalize any written procedures for positioning, installation, and removal of the TMADS and the ROV

Perform mock scenarios to prepare operators and test support personnel for each condition (training)

Document time required to perform each task to be used for estimation of cost and exposure duration to be encountered in tank farm operations 


\subsubsection{Summary of Test Results}

During the course of the GAAT project, some test objectives were revised based on new knowledge and new circumstances. Hoisting and rigging was one of the areas where the objectives changed. Project management decided that it would be the responsibility of the ORNL P\&E Division H\&R group to perform the hoisting and rigging. Therefore, no hoisting and rigging procedures were written, and H\&R used their knowledge and skill to safely lift and set the equipment. Where appropriate "critical lift plans" were used.

No special tools were needed to lift the ROV and its power distribution and control unit. H\&R determined that lifting slings of sufficient load-bearing capacity could be used for the lift.

The system lead observed the equipment installation and performed the necessary steps to connect the equipment following the ROV installation work instructions. Initially it was proposed that the TMADS would be lifted separately from the TMADS stand. Working with H\&R it was determined that time and money, by performing the lift as a single lift with the TMADS, TMADS stand, and extension assembly could save money.

\subsection{ROV DEPLOYMENT, RETRACTION, AND DECONTAMINATION}

\subsubsection{Test Objectives}

The ROV system deployment, retraction and decontamination tests demonstrated the deployment and retraction ability of the ROV through the simulated riser using both the suitcase controller and the console and the effectiveness of the DSR and spray wand at decontaminating the ROV during retraction. Before beginning these test activities, the ROV system was configured in the same manner that it will be installed in the NTF. ${ }^{5}$

Decontamination of the ROV and its tether proved to be challenging. The ROV has many sludge accumulation points, many of which may not be completely decontaminated during DSR operations. Therefore, ROV decontamination activities were performed several times to gather adequate data to document the activity time, exposure time, decontamination water used, and costs for this activity. The initial decontamination tests were completed in conjunction with retraction of the ROV. ${ }^{5}$

The tests were performed using the actual ROV and TMADS and demonstrated the deployment, retraction, and decontamination capabilities and procedures. The ROV equipment was deployed and retracted by the same personnel that are expected to be performing these activities in the tank farm operations; hence, performance of these activities also served to train the personnel. These tests demonstrated the various aspects of the ROV operations and verified the accuracy and completeness of the procedures. ${ }^{5}$

The ROV decontamination testing also demonstrated and verified equipment decontamination methods, determined new decontamination methods that should be used, generated activity and exposure times and other parameters that could be used to determine waste-removal operation costs for tank farm operations. The specific test objectives for the decontamination activities are listed in Table 3.2.1. 
Table 3.2.1 ROV deployment, retraction and decontamination test objectives

Test

Objective

ROV deployment

ROV retraction/

decontamination
Demonstrate and verify the following:

- deployment of ROV through tank riser, and

- deployment into the horizontal position after entering tank

Demonstrate any special tools required, and validate their operability.

Revise and finalize any written procedures for positioning and deployment of the ROV.

Verify ability to perform visual inspection after retraction.

Perform mock scenarios to prepare operators and test support personnel for deployment (training).

Document time required to perform each task for estimation of cost and exposure durations to be encountered in tank farm operations.

Demonstrate and verify the following:

- retraction of ROV through riser after deployment and use, and

- decontamination of ROV using both the DSR and the spray wand as required.

Demonstrate any special tools required, and validate their operability.

Revise and finalize any written procedures for retraction and decontamination of the ROV.

Verify ability to perform visual inspection after retraction and decontamination.

Perform manual wash with the spray wand through the glove ports on the TMADS.

Record water requirements, time requirements, and the number of passes to effectively clean the ROV.

Perform mock scenarios to prepare operators and test support personnel for retraction/decontamination (training).

Document time required to perform each task for estimation of cost and exposure durations to be encountered in tank farm operations. 


\subsubsection{Testing Performed}

\subsubsection{ROV deployment}

The test procedure was modified to delete the requirement to deploy the ROV using the suitcase controller. This requirement was deleted so that the operator could get more practice deploying the ROV from the normal control station. The test procedure was completed successfully with the noted modifications.

\subsubsection{ROV retraction and decontamination}

The test procedure was modified to delete the requirements to (1) retract the ROV using the suitcase controller and (2) use a platform scale to weigh the ROV before and after the test to determine the amount of simulated sludge removed. The first requirement was deleted so that the operator could get more practice retracting the ROV from the normal control station. The second requirement was deleted because no suitable platform scale was available; however, visual observation was determined to be a satisfactory alternative. The test procedure was completed successfully with the noted modifications.

\subsubsection{Summary of Test Results}

Deployment and retraction of the vehicle were performed numerous times throughout the eight months the ROV was installed at the TTCTF. Operators became proficient in this operation. Some difficulty was initially seen in the retraction of the ROV through the riser sleeve. At this point in the operation, the Schilling arm controller cable would occasionally catch on the bottom edge of the riser sleeve. Through trial and error, the operators devised an approach to safely allow the cable and Schilling arm to be retracted into the riser sleeve. This operation was incorporated into the ROV Operation Procedure. An additional difficulty in the deployment and retraction operation was identified when the ROV is stored or released from storage in the TMADS. Because of design constraints on the volume of the TMADS storage area the Schilling arm must be "folded" to allow the TMADS door to close. Folding and unfolding of the arm must be accomplished with an operator on the platform looking through the containment bezel ports and Lexan panels in radio communication with the operator at the controls. This approach was also added to the ROV Operation Procedure.

Decontamination of the ROV was accomplished successfully using the DSR with a nozzle pattern of alternating 25-degree nozzles and 60-degree nozzles. Following the ROV retraction through the operating DSR, some visible simulated sludge from splatter remained on horizontal surfaces and on the tracks. The hand-held spray wand was used for 2 minutes to spray the tether as it was retracted before energizing the DSR and on the vehicle following DSR operations. No visible simulated sludge remained on the ROV after using the spray wand. Determining how much decontamination is required will be based on the radiation levels monitored at the NTF by the radiological control technician.

\subsection{ROV DATA-DISPLAY AND CONTROL SYSTEM}

\subsubsection{Test Objectives}

The ROV data-display and control system consists of controllers for the ROV and manipulator arm, gauges, and video display equipment. The ROV system has two controllers: a suitcase controller and a control console. The tests conducted verified the proper operation of the ROV using each controller. The testing associated with this equipment was used to demonstrate the actions required to properly control and monitor the ROV and its ancillary systems. It also was used to determine the appropriate monitoring and logging activities during ROV operations. Before beginning these test activities, the ROV system was configured in the same manner that it will be after deployment in the NTF. ${ }^{5}$ 
The ROV viewing system was tested to verify its performance and adequacy for the intended operation. The ROV viewing system consists of two cameras and the associated lights. One camera with two lights on a pan and tilt module is located on the rear of the ROV above the right track. The second camera with two associated lights is mounted on the Schilling arm. The viewing system tests were performed so that the two cameras were the only sources of light and viewing for ROV operations. Also, the TTCTF was as dark as possible to simulate tank farm operations. ${ }^{5}$

The tests were performed using the ROV in the deployed configuration and demonstrated the function of the control and data-display equipment. The testing was also used for personnel training of ROV operations and maintenance activities. The specific objectives of each test as listed in the test plan are presented in Table 3.3.1.

Table 3.3.1 ROV data-display and control system test objectives

Test

Data-display and control equipment

Viewing system operations

Viewing system maintenance
Verify that all control and data-display equipment is in place and operates as specified.

Verify proper operation of the ROV using both the control console and suitcase controller.

Establish monitoring and logging requirements for the ROV systems.

Perform mock scenarios for maintenance procedures (training).

Verify that the viewing system components operate properly after installation on the ROV. Information obtained should include:

- field of vision,

- focus,

- lighting design and placement, and

- lens cleaning.

Demonstrate and revise written maintenance procedures for the viewing system components.

\subsubsection{Testing Performed}

\subsubsection{Data-display and control equipment (not listed in Testing Activities)}

No test was conducted for verification of the data-display and control equipment. However, during the course of other testing the data-display and control equipment proved to be adequate and useful.

\subsubsection{ROV viewing system test}

The test procedure was modified and completed successfully. This test was completed by observation during IS testing and open house demonstrations that the installed ROV viewing system was adequate for the project.

\subsubsection{ROV Viewing System Maintenance Test}

The test procedure was followed and completed successfully. 


\subsubsection{Summary of Test Results}

The data-display and control equipment was verified to operate as designed with operation of the ROV from both the control console and the suitcase controller. During the testing, maintenance, and demonstrations, a log system was established by the system lead and has become part of the operating procedures. The viewing system on the ROV proved to be extremely useful for maneuvering the ROV and in assisting the MLDUA and WD\&C systems.

The viewing system maintenance procedures were deleted based on the adoption of the GAAT Work Authorization Procedure. However, some operators were trained on removing the ROV cameras while in the TMADS storage compartment, and P\&E maintenance personnel performed some limited maintenance on the system. Any maintenance other than simple items will most likely have to be performed by the manufacturer of the camera system.

\subsection{ROV OPERATIONS TESTS}

\subsubsection{Test Objectives}

The intended use of the ROV during tank farm operations is multifold. It will be used to control and maneuver the CSEE, plow sludge to the CSEE, collect debris, and wash down debris during cleaning operations. The operations tests were performed to evaluate the ROV capabilities to operate in an environment similar to the anticipated tank environments. Various aspects of ROV operations and reliability were evaluated along with the procedures for operation. ${ }^{5}$

The operations tests involved completing all operating procedures to verify their completeness and accuracy and to provide training opportunities for the operators and maintenance personnel in a nonradioactive environment. Estimates of labor requirements and personnel exposures for implementing operations activities were documented. ${ }^{5}$

The operations testing activities included operation of the ROV; written procedures were followed that have been developed specifically for these activities. Included in the operational tests were evaluations of maneuverability, tether limitations, the manipulator arm, etc. These activities included verifying the operations of each system or piece of equipment and the accuracy of the written procedures. The specific tests and the objectives of each ROV operations test are listed in Table 3.4.1..$^{5}$

Table 3.4.1 ROV operations test objectives

$$
\text { Test Objective }
$$

ROV and manipulator operations
Demonstrate, revise, and finalize written procedures for operation of the ROV and all ancillary support systems (e.g., hydraulics and electrical)

Demonstrate the following:

- operational reliability during ROV maneuvers in the simulated sludge(s),

- maneuverability of the ROV around obstacles in the tanks,

- ability to move, hold, and plow specified payloads in required directions and at attitudes other than horizontal,

- movement limitations/abilities of the manipulator arm,

- tether management control during tank operations, and

- movement limitations/abilities of the ROV. 


\subsubsection{Testing Performed}

\subsubsection{ROV maneuverability test}

The test procedure was modified and completed successfully. The test required that the ROV maneuver and clean around a 2-in.-diam. pipe that was oriented vertically. A concrete block replaced the pipe and the test was performed.

\subsubsection{ROV emergency stop test}

The test procedure was modified and completed successfully. The test required that an emergency stop be initiated from the suitcase controller while operating the ROV from the control console. When the ROV is operated from the control console, the suitcase controller is not connected to the system and initiating an emergency stop from the suitcase controller would have no effect. The same is true when operating the ROV from the suitcase case controller and initiating an emergency stop from the control console. These two tests were not performed. It was demonstrated that the emergency stop switches for the control console and suitcase controller both work as designed.

\subsubsection{ROV operations using only the ROV viewing systems test}

This test procedure was completed successfully.

\subsubsection{Summary of Test Results}

The ROV proved to be highly maneuverable during these series of tests. The two operators who performed a total of seven timed trials quickly learned how to maneuver the ROV and were able to adeptly plow-clean the area around the concrete block. It was observed that in the last four tests the floor was harder to clean because by that point the simulated sludge had become well mixed and the density had decreased. During the last four tests, the simulated sludge tended to flow back into the area from where it had been plowed. It was also observed during the test that the operator had to pay close attention to the ROV tether during plowing, keeping enough unreeled to maneuver but not so much that the tether lies on the floor and drags sludge back into the cleaned area.

The ROV camera system proved to be adequate to handle the task of debris management by itself. However, it was deemed to be inadequate during maneuvering of the ROV because of the need to closely monitor the length of tether that was out. It will most likely be necessary to shutdown ROV operations following a loss of the overview cameras because of a lack of ability to observe the tether.

\subsection{ROV MAINTENANCE TESTS}

\subsubsection{Test Objectives}

Because the ROV has many moving parts that will be exposed to the sludge, it was anticipated that preventive maintenance could be a significant contributor to extending the life of the ROV as well as to minimizing unexpected downtime. The ROV maintenance tests were performed to gather cost and timing information, as well as to train personnel in a nonhazardous environment. The objectives of the ROV maintenance tests are detailed in Table 3.5.1. These tests verified the written procedures and permitted training of personnel. ${ }^{5}$

\subsubsection{Testing Performed}

\subsubsection{ROV maintenance test}

The track replacement, hydraulic systems filter replacement, TMADS glove replacement, tether termination pin replacement, and track drive motor replacement tests were completed successfully. 
Table 3.5.1 ROV maintenance test objectives
Test
Objective

ROV maintenance

Perform routine maintenance; and demonstrate, revise, and finalize written procedures for maintenance of the ROV and its ancillary systems.

Demonstrate the function and effectiveness of the decontamination spray ring for decontamination of the ROV for maintenance. Record water requirements, time requirements, and the number of passes to effectively clean the ROV.

Perform mock maintenance scenarios for the maintenance procedures (training).

Document the time required to perform each task for an estimation of cost and exposure durations to be encountered in tank farm operations.

\subsubsection{Summary of Test Results}

Each maintenance test was performed to varying degrees of training simulation. Some of the more difficult tests were performed in the test pit early in the testing phase, while latter tests were completed with simulated radiological work permits, radiological control technician support, full personal protective equipment (PPE), and various other simulations to make for better training. Several things were learned during the maintenance testing that were captured and that will be used later in developing any work instructions that may be needed.

\subsection{ROV CAMERA LENS CLEANING OPERATIONS TEST}

\subsubsection{Test Objectives}

The ROV camera lens cleaning tests were performed during the mining strategy or scarifying operations as necessary. ${ }^{5}$

Also, each activity specified the number of times, if any, that the activity was to be completed by staff while wearing the appropriate PPE. If the test required PPE, guidance was obtained from health physics personnel concerning the appropriate level of PPE for similar activities that will be performed in the STF. Form TP-30 to log PPE was used to document information. ${ }^{5}$

\subsubsection{Testing Performed}

\subsubsection{Specified tests}

The ROV camera lens cleaning test procedure was followed and was completed successfully.

\subsubsection{Summary of Test Results}

The ROV camera lens cleaning system incorporates a timer that starts when the lens-cleaning button is depressed on the control console. When the button is depressed it allows water to flow and be directed to the camera lens by air pressure, which then continues after the water flow stops to clear the line and blow off any residual sludge on the camera lens. The total time for cleaning is two minutes. When the timer completes its cycle, it will shut down the airflow to the lens. In all instances the system performed as designed and is a valuable support system for the ROV camera system. 


\subsection{MINING STRATEGY TESTS}

\subsubsection{Test Objectives}

Various mining strategies are currently being considered to successfully remove the sludge from the GAAT. These include IS movements, wall-cleaning operations, and cleaning in corners and around pipes. ${ }^{5}$

The mining strategy tests were performed using the actual ROV, WD\&C, and balance of plant (BOP) equipment and were used to develop procedures and determine which strategies are most effective at sludge removal. The specific objectives of each test are presented in Table 3.7.1.

\subsubsection{Testing Performed}

\subsubsection{Stationary ROV operations test}

The test procedure was modified and completed successfully. The test procedure was modified to make it a combination of stationary ROV operations and mobile ROV operations. The modification was made based on operator knowledge and experience with the system.

\subsubsection{IS movements test}

The test procedure was followed and completed successfully.

Table 3.7.1 Mining strategy test objectives

Test

Objective

Stationary ROV mining

Mobile ROV mining

IS movement methods

Wall cleaning by ROV

Cleaning of corners and around pipes
Evaluate mining strategy where the vehicle is stationary while the CSEE is moved to the floor, which simulates cleaning patches of the floor.

Verify that the preferred cutting jet operating pressure and rotational speed for the CSEE cutting system are acceptable during integrated system movements.

Evaluate mining strategy where the vehicle is moved while the CSEE is operated, which simulates cleaning strips of the floor.

Verify that the preferred cutting jet operating pressure and rotational speed for the CSEE cutting system are acceptable during integrated system movements.

Demonstrate the integrated movements of the ROV and the HMA.

Evaluate the effectiveness of wall-cleaning activities, and determine an appropriate cutting system pressure.

Document time required for wall cleaning.

Demonstrate, revise, and finalize written procedures for cleaning around pipes.

Document time required for cleaning around pipes. 


\subsubsection{Mobile ROV operations test}

The test procedure was modified and completed successfully. The test procedure was modified such that it was a combination of stationary ROV operations and mobile ROV operations. The modification was made based on operator knowledge and experience with the system.

\subsubsection{Wall-cleaning test}

The test procedure was modified and completed successfully.

\subsubsection{Cleaning of corners and around pipes test}

The test procedure was followed and completed successfully.

\subsubsection{Summary of Test Results}

The stationary ROV operations and mobile ROV operations test procedures were modified and combined into one procedure. The modification was made based on operator knowledge and experience with the system. The operator initially positioned the ROV in an area that needed to have simulated sludge removed. After the sluicing system was started, the CSEE was placed in the sludge to the desired depth. Once the CSEE was at the desired depth, the Schilling arm wrist, elbow, and shoulder joints were locked, allowing the operator to move the CSEE about the shoulder azimuth and thus maintain a constant depth with the CSEE. The CSEE would then be moved within the limits of the HMA and the Schilling arm to remove simulated sludge. As a swath was "cut" into the sludge, the ROV would be moved either forward or backward approximately 4 in. to clean a new area. This combination of movements proved to be within the capabilities of the equipment and the abilities of the operator and effectively removed the sludge. It was also observed that the efficiency of sludge removal increased as the operator gained experience in the mining operation.

During the combined stationary and mobile mining testing it was found that if process water pressure was applied to the cutting jets rather than an increased pressure from the high pressure cutting jet water pump (L-02), less water was used and the cutting jets remained clear of debris. It was, however, necessary at times to boost the cutting jet pressure to 1000 psi. This increase in pressure was necessary to "blow" debris out of the influence of the jet pump suction to avoid clogging the inlet screen. The CSEE rotation was maintained at a constant 210-rpm (1.5 V) during all the testing.

The IS movement test with the HMA revealed no integration problems between the ROV and the HMA. During the portion of testing where the ROV is operated within a 4-ft. radius of the HMA, the second link of the HMA caught on the stop ring and broke it. The stop ring was redesigned and retested manually with no problems noted.

The wall-cleaning test was performed using a painted area of the wall in the test pit, and the cleaned area was measured following the test. This test was also performed as a combination of stationary and mobile ROV operation. Using the experience learned from the sludge mining tests, the operator initially positioned the ROV in an area close to the wall with the tracks parallel to the wall and then positioned the CSEE close to the wall at either the lowest or highest position it could reach. After the cutting system was then started, the Schilling arm wrist, elbow, and azimuth joints were locked, allowing the operator to move the CSEE about the shoulder thus and maintain a constant standoff distance from the wall with the CSEE. The CSEE would then be moved within the limits of the HMA and the Schilling arm to clean the wall. As a swath was cleaned, the ROV would be moved either forward or backward approximately 4 -in. to clean a new area. This combination of movements proved to be within the capabilities of the equipment and the ability of the operator and effectively cleaned the wall. It was also observed during this testing that the efficiency of wall cleaning increased as the operator gained experience in the operation.

Cleaning around corners and pipes was done as a washing method with the CSEE cutting jets held at a standoff distance of at least 1 -ft. The only area that proved to be challenging for cleaning was the corner of the test pit. However, because there are no corners in the GAAT this is not a significant finding. 


\subsection{DEBRIS MANAGEMENT TESTS}

\subsubsection{Test Objectives}

Each of the GAAT contains some amount of miscellaneous debris. The current plan is to collect and remove all debris except for chunks of Gunite. The Gunite chunks will be collected in a designated area within the tank and will be washed to remove sludge. The debris management tests tested procedures for movement and washing of specific items that may be encountered during tank farm operations. ${ }^{5}$

The tests were performed using the ROV and the CSEE. Specific tests and their objectives are presented in Table 3.8.1.

Table 3.8.1 Debris management test objectives

\begin{tabular}{ll}
\hline \multicolumn{1}{c}{ Test } & \multicolumn{1}{c}{ Objective } \\
\hline Debris movement & $\begin{array}{l}\text { Demonstrate and verify the debris movement operations and } \\
\text { procedures using the ROV arm and plow. } \\
\text { Document the time required for debris movement. } \\
\text { Debris wash down }\end{array} \quad \begin{array}{l}\text { Demonstrate and verify the debris wash-down operations and } \\
\text { procedures using the ROV water system and the CSEE cutting }\end{array}$ \\
$\begin{array}{l}\text { jets. } \\
\text { Down of debris. }\end{array}$ \\
\hline
\end{tabular}

\subsubsection{Testing Performed}

\subsubsection{Debris management test}

This test procedure was modified to delete decontamination and wash down of the debris. The modified test was completed successfully.

\subsubsection{Debris washing using the ROV water line}

This test procedure was deleted.

\subsubsection{Debris washing using the CSEE}

This test procedure was deleted.

\subsubsection{Summary of Test Results}

The operator at the controls was able to move all the debris to the "clean" area in one instance using both the plow and arm, reducing the time required to move all the debris. As the wash down of the debris was discussed, the operator recommended using a remote radiation probe to determine the radiation level of the debris before performing the wash down. If the radiation is considered to be low level, then the debris could be removed and bagged and no additional water added to the waste stream. The total time to move all the debris to the clean area was slightly more than 8.5 minutes. 


\subsection{SCARIFYING OPERATIONS TESTS}

\subsubsection{Test Objectives}

The Gunite tank inner walls have been exposed to radioactive materials and may require scarifying to remove the inner layer of Gunite that has absorbed radioactive material. The CSEE has been designed to break up and fluidize sludge and make it transferable. These testing activities were designed to evaluate the unit's scarifying ability. ${ }^{5}$

The scarifying operations tests were performed at the TTCTF. This testing demonstrated and verified the ability of the CSEE to remove an incremental layer from a Gunite surface. Two types of materials were used for this test: a Gunite panel and a panel consisting of Gunite mixed with tar. ${ }^{5}$

\subsubsection{Testing Performed}

\subsubsection{Scarifying test}

The test procedure was modified and completed successfully.

\subsubsection{Summary of Test Results}

The scarifying test was performed in conjunction with the wall-cleaning test using a painted area of the wall in the test pit. Following the test, the area was measured. This test was performed as a combination of stationary and mobile ROV operation. Using the experience learned from the sludge mining tests, the operator initially positioned the ROV in an area close to the wall with the tracks parallel to the wall and then positioned the CSEE close to the wall either at the lowest or highest position it could reach. After the cutting system was started, the Schilling arm wrist, elbow, and azimuth joints were locked, and allowing the operator to move the CSEE about the shoulder and thus maintain a constant standoff distance from the wall with the CSEE. The CSEE would then be moved within the limits of the HMA and the Schilling arm to scarify the wall. As a swath was scarified the ROV would be moved either forward or backward approximately 4 in. to scarify a new area. This combination of movements proved to be within the capabilities of the equipment and the abilities of the operator and effectively cleaned the wall. It was also observed during this testing that the efficiency of wall cleaning increased as the operator gained experience in the operation.

\subsection{FAILURE MODE TEST}

\subsubsection{Test Objectives}

The ROV was to be configured to permit release of the CSEE in the event of a failure of the ROV. This test was used to evaluate the ability of the ROV arm to release the CSEE in various failure modes. ${ }^{5}$

The failure mode testing activities included an evaluation of whether the ROV would release the CSEE in the event of a failure. The specific tests and the objectives for each test are listed in Table $3.10 .1 .^{5}$ 
Table 3.10.1 Failure mode test objectives

Failure mode

Observe the ROV's reaction to the CSEE operational forces

during the following failure modes

Evaluate the ROV Schilling Arm's ability to release each

CSEE handle during the following failure scenarios:

- total power loss to vehicle,

- total hydraulic pressure loss to vehicle,

- power loss to the Schilling arm, and

- hydraulic pressure loss to the Schilling Arm.

\subsubsection{Testing Performed}

\subsubsection{Failure mode test}

The test procedure was modified so that the test would not be repeated while simulating scarifying operations because the results would be the same. The test was completed successfully.

\subsubsection{Summary of Test Results}

The ROV performed as designed under all test conditions. Each time the power or hydraulic pressure was removed from the vehicle, the gripper would release the CSEE. A nonfunctional mock CSEE was used in the testing rather than the operational CSEE; hence, there were no unusual forces acting on the ROV from the CSEE.

\subsection{CAMERA LIGHTING INFORMATION}

\subsubsection{Test Objectives}

The camera and lighting information was gathered for all the camera and lighting equipment that will be used during NTF operations. This information was collected during any and all of the previously listed testing activities. This section details the information collected. ${ }^{5}$

The checklist contained in this subsection was not intended to be completed as a separate checklist but rather to be considered during the other IS tests. The intent of this checklist was to report observations concerning the adequacy of the camera and lighting equipment to assist in the in-tank operations. Specific things that were considered during the other testing include but were not limited to the following:

- Adequacy of the cameras at enabling the operators to view all areas during each test activity, (i.e., was it necessary to use other nontest equipment or people to coordinate certain activities, such as grasping the CSEE).

- Adequacy during low-light periods to permit remote viewing of the operations using the camera system.

\subsubsection{Testing Performed}

\subsubsection{Camera and lighting tests}

Test procedure was followed and completed successfully. 


\subsubsection{Summary of Test Results}

The camera system on the ROV was determined to be adequate to assist the operators in viewing the tank. However, the onboard system was not adequate to provide the operator with all the necessary views for operation. The operator needed the overview cameras to provide views of the tether that was payed out in addition to assisting in the retraction of the ROV through the riser sleeve.

\subsection{INTEGRATED SYSTEM (ROV, MLDUA, AND WD\&C) MINING TESTS}

\subsubsection{Test Objectives}

The ROV, MLDUA, and WD\&C systems were designed to work together to retrieve the sludge from the tanks. When the ROV is not able to maneuver in the sludge, the MLDUA will grasp the CSEE and perform mining operations. However, it is expected that once a small area of the tank has been cleared, using the ROV plow to move the sludge to the CSEE (held by the MLDUA) is an acceptable mining approach. Therefore, the tests in this section addressed this approach and debris management issues. $^{5}$

The three-system (ROV, MLDUA, and WD\&C) mining and debris-washing approaches were evaluated during this testing. The specific objectives of each test are presented in Table 3.12.1.

Table 3.12.1 Integrated system mining test objectives

Test Objective

ROV, MLDU, and CSEE integrated sludge removal

Debris washing
Evaluate mining strategy where the MLDUA holds the CSEE in a small area while the ROV plows sludge to that point.

Evaluate the ability of the ROV water supply to clean the debris while the MLDUA positions the debris. Record the water and time requirements.

Evaluate the ability of the CSEE (managed by the ROV) to clean the debris while the MLDUA positions the debris, and evaluate the reverse. Record the water and time requirements.

\subsubsection{Testing Performed}

\subsubsection{IS sludge removal test}

This test procedure was completed successfully.

\subsubsection{IS debris washing test}

This test procedure was modified. The ROV performed debris collection while the MLDUA was used to wash debris using the CSEE. The modified test procedure was completed successfully.

\subsubsection{Summary of Test Results}

Use of the ROV to plow sludge to the CSEE held at a minimal standoff from the tank floor was found to be a highly effective approach for sludge removal. This approach has the advantage of an improved retrieval rate because a rich slurry mixture is constantly being moved within the region of influence of the jet pump vacuum. In the TTCTF, which is approximately the same size as the NTF tanks, care was required to avoid collisions of the three major systems. In the larger STF tanks this will be less of a concern. 
The three rotating jet nozzle on the CSEE makes it an effective tool for washing sludge away from debris. The MLDUA has adequate dexterity to deliver the CSEE jet spray over a wide area to wash debris. However, because of the combined mobility and dexterity of the ROV, it is also an excellent system for washing debris with the CSEE. The ROV is clearly the preferred system for debris collection. 


\section{WASTE DISLODGING AND CONVEYANCE SYSTEM AND BALANCE OF PLANT EQUIPMENT TESTING}

Performance tests of the WD\&C system and auxiliary equipment are delineated in Ref. 6 . The testing performed is described in the following paragraphs.

\subsection{DECONTAMINATION SPRAY RING COMPONENT TESTS}

\subsubsection{Test Objectives}

The DSR uses high pressure (up to 2,100 psig working pressure) to remove sludge from the HMA, MLDUA, and ROV before retraction from the tank environment. The DSR was one of the first components to arrive on site. Therefore, the DSR component tests were performed without the presence of the other components. This testing was independent of and before the remainder of the WD\&C system performance tests. ${ }^{6}$

The component testing of the DSR was performed at the ORNL TTCTF when the DSR arrived on site. The testing was performed to verify that (1) all components of the DSR and riser sleeve were present, (2) the DSR and riser sleeve could be installed onto a tank as required, and (3) that the components operated as required. The objectives of the tests are listed in Table 4.1.1. ${ }^{6}$

Table 4.1.1 Decontamination spray ring component test objectives

\begin{tabular}{ll}
\hline \multicolumn{1}{c}{ Test } & \multicolumn{1}{c}{ Objective } \\
\hline Installation & $\begin{array}{l}\text { Verify that installation procedures are adequate and } \\
\text { complete. } \\
\text { Document time required to complete installation. } \\
\text { Decontamination }\end{array}$ \\
$\begin{array}{l}\text { Demonstrate the function and effectiveness of the } \\
\text { decontamination process on cylinders using two nozzle } \\
\text { configurations. }\end{array}$ \\
\hline
\end{tabular}

\subsubsection{Testing Performed}

4.1.2.1 DSR and riser sleeve installation testing

Th test procedure was followed and completed successfully.

\subsubsection{DSR removal testing}

The test procedure was followed and completed successfully.

\subsubsection{DSR coverage testing}

The test procedure was modified and completed successfully. The test was modified to use the prototype Houdini vehicle instead of the test cylinders to determine the best mix of spray nozzles for the ROV. Also, the test was modified to use only one size pipe (10-in.-diam to mock the MLDUA). 


\subsubsection{Sludge removal testing}

The test procedure was modified and completed successfully. The test was modified to use the prototype Houdini vehicle instead of the test cylinders to determine the best mix of spray nozzles for the ROV. Also, the test was modified to use only one size pipe (10-in.-diam).

\subsubsection{Summary of Test Results}

DSR testing was performed as the first tests to be conducted in the TTCTF. Installation and removal testing validated the procedures with minimal revision and determined the time required for these activities to be approximately 15 minutes each.

DSR coverage testing and sludge removal testing determined the dispersion angles of nozzles required in each of the spray rings. For the MLDUA and HMA, the best mix was determined to be using $65^{\circ}$ fan nozzles. Observing the effect of the spray on the 10-in. cylinders made this determination. For the ROV, the best mix of nozzles was determined to be alternating $65^{\circ}$ nozzles and $25^{\circ}$ nozzles after observing the effects on the prototype vehicle.

\subsection{FLOW CONTROL EQUIPMENT AND CONTAINMENT BOX FUNCTIONAL TESTS}

\subsubsection{Test Objectives}

The flow control equipment and containment box (FCE/CB) is composed of piping, valves, a slurry sampling system, and a flow meter. Components included in the FCE/CB will be used during GAAT Treatability Study operations to measure slurry flow rates and to safely collect slurry samples. This testing was independent of the other WD\&C system performance tests and was included in the test plan to minimize the cost of producing such test plans. ${ }^{6}$

The functional testing of the FCE/CB was used to verify that the FCE/CB components operated as required by the specifications and to establish preliminary accuracy measurements for the flow meter. The FCE/CB components were operated while water and simulated sludge was transferred through the FCE/CB. Specific FCE/CB tests and the objectives of each test are listed in Table 4.2.1. ${ }^{6}$

\section{Table 4.2.1 FCE/CB functional test objectives}

\begin{tabular}{ll}
\hline \multicolumn{1}{c}{ Test } & \multicolumn{1}{c}{ Objective } \\
\hline Flow meter performance & $\begin{array}{l}\text { Demonstrate the flow meter accuracy and repeatability when } \\
\text { measuring one- and two-phase flow (water and sludge). }\end{array}$ \\
Valve operations & $\begin{array}{l}\text { Verify the proper operation of the flow control valve during } \\
\text { pumping simulated sludge through the FCE/CB. }\end{array}$ \\
Proportional sampler & $\begin{array}{l}\text { Verify the proper operation of the sampler while pumping } \\
\text { simulated sludge through the FCE/CB. }\end{array}$ \\
& $\begin{array}{l}\text { Demonstrate, revise, and finalize hot sampling procedures for } \\
\text { collection of each type of sample (i.e., sludge, slurry, water). }\end{array}$ \\
& $\begin{array}{l}\text { Ensure operator familiarity with sampling equipment } \\
\text { operations and sample collection/shipment protocols.. }\end{array}$ \\
& $\begin{array}{l}\text { Simulate flushing of the FCE/CB box to demonstrate } \\
\text { decontamination effectiveness through flushing. Identify } \\
\text { potential locations for sludge to accumulate. Demonstrate } \\
\text { each component's ability to drain. Identify low points that } \\
\text { may collect solids and/or water. }\end{array}$ \\
Decontamination & $\begin{array}{l}\text { Demonstrate hot maintenance of each component through } \\
\text { access panels. }\end{array}$ \\
\hline
\end{tabular}




\subsubsection{Testing Performed}

\subsubsection{FCE/CB installation}

The test procedure was followed and completed successfully.

\subsubsection{FCE/CB single phase flow measurement test}

The test procedure was modified and completed successfully. The test was modified to capture the flow rate using a bucket to capture the discharge flow in a designated time period instead of a rotometer because a suitable one was not available.

\subsubsection{FCE/CB two-phase flow measurement test}

The test procedure was followed and completed successfully. The test was modified to capture the flow rate using a bucket to capture the discharge flow in a designated time period instead of a rotometer because a suitable one was not available.

\subsubsection{FCE/CB proportional sampler and valve operations test}

- sampling

- decontamination

- maintenance

The test procedure was followed and completed successfully.

\subsubsection{Summary of Test Results}

The single-phase flow tests proved that under single-phase flow the mass flow meter was reliable and repeatable. However, under two-phase flow the mass flow meter was not reliable for flow rate but was reliable and repeatable for total flow measured.

The FCE/CB proportional sampler and valve operations test proved that the proportional sampler would take a 10-ml sample each time it is activated either manually or when set up for automatic operation. During testing, the flow control valve was identified as a potential line plugging point. Through the project configuration management plan this valve was removed from the system. The system flushing proved to be very effective at removing sludge in the piping and at a minimal expenditure of process water to the tanks. This was mostly because the sludge would drain by gravity back to either the receiving tank or the source tank.

Some maintenance activities were captured on the FCE/CB, which helped identify trouble spots. Again, the configuration management plan was used to address the trouble spots.

\subsection{Hose Management System Installation Tests}

\subsubsection{Test Objectives}

The HMS installation tests included installation/removal, and assembly/disassembly of the HMS and CSEE. Before beginning these test activities, the system was configured in the same manner that it will be installed in the NTF. ${ }^{6}$

The HMS installation tests were accomplished using the hoisting and rigging, installation, assembly, checkout, and disassembly procedures. This section presents the details of the WD\&C system installation activities at the TTCTF. ${ }^{6}$

The tests were conducted using the actual HMS and BOP equipment and demonstrated the various installation aspects of the HMS and verified the accuracy and completeness of the procedures. The 
equipment was transported, installed, and removed by the same personnel who are expected to be performing these activities in the tank farm operations so that performance of these activities could also serve to train the personnel. The specific objectives of each test as listed in the test plan are presented in Table 4.3.1.

Table 4.3.1 HMS installation test objectives

\begin{tabular}{|c|c|}
\hline Test & Objective \\
\hline \multirow[t]{3}{*}{ Hoisting and rigging } & $\begin{array}{l}\text { Demonstrate and verify hoisting and rigging equipment } \\
\text { operations and procedures. }\end{array}$ \\
\hline & $\begin{array}{l}\text { Demonstrate any special tools required for hoisting and } \\
\text { rigging and validate their operability. }\end{array}$ \\
\hline & $\begin{array}{l}\text { Document time required to perform hoisting and rigging } \\
\text { operations for estimation of cost and exposure durations to be } \\
\text { encountered in tank farm operations. }\end{array}$ \\
\hline \multirow[t]{3}{*}{ System assembly } & $\begin{array}{l}\text { Demonstrate and verify equipment operations and } \\
\text { procedures. }\end{array}$ \\
\hline & $\begin{array}{l}\text { Demonstrate any special tools required for system assembly } \\
\text { and validate their operability. }\end{array}$ \\
\hline & $\begin{array}{l}\text { Document the time required to perform system assembly } \\
\text { operations for an estimation of cost and exposure durations to } \\
\text { be encountered in tank farm operations. }\end{array}$ \\
\hline \multirow[t]{3}{*}{ System disassembly } & $\begin{array}{l}\text { Demonstrate and verify equipment operations and } \\
\text { procedures. }\end{array}$ \\
\hline & $\begin{array}{l}\text { Demonstrate any special tools required for system } \\
\text { disassembly and validate their operability. }\end{array}$ \\
\hline & $\begin{array}{l}\text { Document time required to perform system disassembly } \\
\text { operations. }\end{array}$ \\
\hline \multirow[t]{3}{*}{ HMS checkout } & $\begin{array}{l}\text { Verify that the HMS is properly installed, connected, and } \\
\text { operational. }\end{array}$ \\
\hline & Demonstrate and verify procedures. \\
\hline & $\begin{array}{l}\text { Document the time required to perform system disassembly } \\
\text { operations. }\end{array}$ \\
\hline
\end{tabular}

\subsubsection{Testing Performed}

\subsubsection{HMS installation}

The test procedure was followed and completed successfully. 


\subsubsection{HMS removal}

The test procedure was followed and completed successfully.

\subsubsection{Summary of Test Results}

The installation and removal tests verified the hoisting and rigging operations and lift plans as conducted by H\&R. No special tools were required for the operation, which were completed in approximately 1 hour. The system assembly, disassembly, and checkout tests were performed and validated the work instructions and procedures.

\subsection{HMS DEPLOYMENT/RETRACTION TESTS}

\subsubsection{Test Objectives}

The HMS deployment/retraction tests included deployment and retraction of the HMS and CSEE. Before beginning these test activities, the system was configured in the same manner that it will be installed in the NTF. ${ }^{6}$

The tests were conducted using the actual HMS and demonstrated the deployment and retraction capabilities and procedures. The equipment was deployed and retracted by the same personnel who are expected to be performing these activities in the tank farm operations so that performance of these activities could also serve to train the personnel. These tests demonstrated the various aspects of HMS operations and verified the accuracy and completeness of the procedures. The specific objectives of each test as listed in the test plan are presented in Table 4.4.1. ${ }^{6}$

Table 4.4.1 HMS deployment/retraction test objectives

Test

Objective

System deployment/retraction Demonstrate and verify deployment/retraction operations and procedures.

\subsubsection{Testing Performed}

\subsubsection{HMS deployment and retraction test}

The test procedure was followed and completed successfully.

\subsubsection{Summary of Test Results}

The HMS deployment and retraction tests were conducted during the acceptance testing. A problem was found during the testing, with the ratchet bar, that it created interference that would not allow the HMA to deploy and retract smoothly. Through the configuration management plan, the ratchet bar was removed and the tests conducted again satisfactory. A mechanical stop was provided to prevent inadvertent lowering of the HMA.

\subsection{WD\&C OPERATION TESTS}

\subsubsection{Test Objectives}

After the WD\&C sluicing subsystem and BOP startup/shutdown tests were completed and the unit prepared for simulated operations, the WD\&C operations tests were performed. The cutting subsystem was not tested during these activities but were tested during the IS test. ${ }^{6}$ 
Included in these tests were FCE/CB and DSR operations testing activities. These activities included verifying that the FCE/CB controls operate as required after integration with the WD\&C system and verifying the DSR's effectiveness at removing material from the CSEE and HMS. ${ }^{6}$

The operations tests involved completing all operating procedures to verify their completeness and accuracy and to provide training opportunities for the operators and maintenance personnel in a nonradioactive environment. These testing activities were used to determine the effectiveness of the WD\&C at removing the slurry from the tank and the potential for sludge to deposit in the transfer lines. Estimates of labor requirements and personnel exposures for implementing operations activities were documented.

The operations testing activities included operation of the WD\&C sluicing subsystem and the BOP systems and followed written procedures developed specifically for these activities. Included in the operational tests were multiphase pumping, controls, HMS kinematics, jet pump operations, camera and lighting equipment placement, and operation mining strategies. These activities included verifying the operations of each system or piece of equipment and the accuracy of the written procedures. The specific tests and the objectives of each are listed in Table 4.5.1. ${ }^{6}$

Table 4.5.1 WD\&C operation test objectives

\begin{tabular}{|c|c|}
\hline Test & Objective \\
\hline Multiphase pumping & $\begin{array}{l}\text { Determine the following: } \\
\text { - pumping effects in suction line during sludge pumping, } \\
\text { pumping effects in horizontal piping following jet pump on, } \\
\text { - pumping sludge, } \\
\text { - } \quad \text { sotential for sludge deposition in transfer lines for various, and } \\
\end{array}$ \\
\hline HMS kinematics & $\begin{array}{l}\text { Demonstrate sludge transfer through the full range of motion for the } \\
\text { HMS in both the passive and active modes. }\end{array}$ \\
\hline \multirow[t]{3}{*}{ Startup/shutdown } & $\begin{array}{l}\text { Demonstrate and verify the following: } \\
\text { - equipment operation, and } \\
\text { - adequacy and accuracy of the written procedures. }\end{array}$ \\
\hline & $\begin{array}{l}\text { Determine the control coordination requirements during startup and } \\
\text { shutdown operations for BOP equipment (start/stop high-pressure } \\
\text { pumps, etc.) }\end{array}$ \\
\hline & $\begin{array}{l}\text { Record operation times and other parameters that could be used to } \\
\text { determine waste-removal operation costs. }\end{array}$ \\
\hline \multirow[t]{4}{*}{ Operation } & Verify the system's independent controls. \\
\hline & $\begin{array}{l}\text { Verify the desired operating envelope for the jet pump using } \\
\text { varying sludge densities. Determine the following: } \\
\text { - amount and percent of solids removed per operating time, } \\
\text { - rate of motive fluid required, } \\
\text { - conte of slurry discharged, } \\
\text { - integration into the system. }\end{array}$ \\
\hline & $\begin{array}{l}\text { Document equipment and instrument failures and mean time } \\
\text { between failures. }\end{array}$ \\
\hline & Evaluate the effectiveness of line flushing. \\
\hline
\end{tabular}




\subsubsection{Testing Performed}

\subsubsection{WD\&C sluicing subsystem and BOP checkout}

The test procedure was followed and completed successfully.

\subsubsection{WD\&C Sluicing subsystem and BOP startup and shutdown}

The test procedure was followed and completed successfully.

\subsubsection{WD\&C sluicing subsystem emergency stop test}

Test procedure was followed and completed successfully.

\subsubsection{Sluicing test}

Two-phase pumping

Multiphase pumping

\subsubsection{Debris pumping test}

The test procedure was followed and completed successfully.

\subsubsection{Summary of Test Results}

During testing it was determined that (1) there was minimal adverse affect on the suction line or horizontal piping during sludge transfer through the full range of motion for the HMS and (2) because of the design of the transfer piping the potential for sludge deposition in transfer lines for various sludge densities was minimized.

It was determined that approximately 15 gal. of sludge could be removed for 10 gal. of motive fluid for a total of approximately $25 \mathrm{gpm}$.

\subsection{BALANCE OF PLANT TESTS}

\subsubsection{Test Objectives}

The BOP system tests were performed for the various pumps, air compressor, decontamination spray system, and other ancillary equipment that will be used during NTF operations.

These tests included all activities to install, checkout, and operate the BOP systems that will be used during NTF operations. These activities were conducted in accordance with previously developed written procedures. Some BOP tests were conducted in conjunction with WD\&C testing activities. The specific tests and test objectives are listed in Table 4.6.1.

\subsubsection{Testing Performed}

4.6.2.1 BOP equipment installation, checkout, and removal test

The test procedure was followed and completed successfully.

\subsubsection{BOP operations test}

The test procedure was followed and completed successfully.

\subsubsection{BOP maintenance}

The test procedure was followed and completed successfully. 
Table 4.6.1 Balance of plant test objectives

Test

Objective

Installation

Verify that installation procedures are adequate and complete.

Document the time required to complete installation.

Equipment checkout Verify that checkout procedures are adequate and complete.

Document the time required to complete equipment checkout.

Operations $\quad$ Verify that operations procedures are adequate and complete.

Failure

Demonstrate the maintenance requirements for failed BOP equipment.

\subsubsection{Summary of Test Results}

During testing the installation and operations work instructions and procedures were refined and validated as adequate and complete. The maintenance requirements were not demonstrated because the BOP equipment had no significant failures during testing.

\subsection{WD\&C IN-PLACE MAINTENANCE TESTS}

\subsubsection{Test Objectives}

The HMS in-place maintenance tests were performed on the various parts of the system that may require either maintenance because of operations failures or scheduled or routine maintenance requirements. Maintenance took place either at or in proximity to the operations area (a later section details maintenance activities that must occur in the lay-down area). These tests included all activities to properly repair or replace the system parts. These activities were conducted in accordance with previously developed written procedures. ${ }^{6}$

All maintenance activities were performed to simulate NTF operations. Therefore, personnel performing these activities donned appropriate PPE. ${ }^{6}$

The in-place maintenance test activities were used to prepare maintenance personnel for safely conducting maintenance activities on equipment that has been exposed to potentially contaminated material and to verify the written procedures. The specific tests and the objectives of each WD\&C inplace maintenance test are listed in Table 4.7.1.

\subsubsection{Testing Performed}

\subsubsection{Total system power loss failure test}

The test procedure was followed and completed successfully.

4.7.2.2 Power loss to individual critical components test

The test procedure was followed and completed successfully. 
Table 4.7.1 WD\&C in-place maintenance test objectives

Test

Objective

Failure recovery

Demonstrate system reaction as defined in design

specifications and recovery from failures that may include the following:

- power loss to total system,

- power loss to individual critical components, and

- conveyance line rupture.

Pump change-out

Determine pump change-out time, and verify change-out procedures.

CSEE change-out

Determine CSEE change-out time, and verify change-out procedures.

Hose bundle replacement

Determine hose bundle replacement time, and verify replacement procedures.

Hose changeout (top section)

Determine slurry hose (top section) change-out time, and verify change-out procedures.

Rupture disk replacement Determine rupture disk replacement time, and verify replacement procedures.

\subsubsection{Line plugging test}

The test procedure was followed and completed successfully.

\subsubsection{CSEE maintenance test}

The test procedure was modified and completed successfully. This test was performed by P\&E in their shop rather than in the confinement box.

\subsubsection{WD\&C in-place maintenance test}

WD\&C in-place maintenance activities were performed for rupture disk replacement. Other in-place maintenance activities were performed as needed during cold testing. It was learned during testing that many of the maintenance activities will have to be performed in a lay-down area and not in place.

\subsubsection{Summary of Test Results}

The system was subjected to a total power loss during validation of the loss-of-power procedure and did not react in any manner out of the ordinary. All systems were safely shut down in sufficient time so that surplus power was available on the uninterruptible power supply.

The jet pump and CSEE change-out times were not accurately determined because these activities were performed in the test pit and not in the confinement box. Because of the nature of these activities, however, they will be relatively minor tasks if a change out is required.

The hose bundle and slurry hose (top section) replacement times were not captured because these activities will have to be conducted in a lay-down area.

The rupture disk replacement was conducted before moving the equipment to the NTF. It took approximately a full shift to complete this task. 


\subsection{MAINTENANCE AT MOCK LAY-DOWN AREA TESTS}

\subsubsection{Test Objectives}

The WD\&C maintenance tests that had to be completed in the mock lay-down area were performed on the various parts of the WD\&C system that may require either maintenance because of operations failures or scheduled maintenance requirements. These tests included all activities to properly repair or replace the system part. This section details the operations test activities. ${ }^{6}$

These tests included all activities to transport the WD\&C to the mock lay-down area and perform the required maintenance on the WD\&C. These activities were conducted in accordance with previously developed written procedures. The specific tests and the objectives of each WD\&C maintenance test at the mock lay-down area are listed in Table 4.8.1.

Table 4.8.1 Maintenance at mock lay-down area test objectives

Test

Objective

Maintenance at mock laydown area
Perform:

- system transport to maintenance area, and

- maintenance action simulations in mock lay-down area.

Demonstrate the following maintenance activities that must be performed at the mock lay-down area and that may include the following:

- swivel joint seal replacement, and

- maintenance procedures for unplanned breakdowns as they arise.

\subsubsection{Testing Performed}

\subsubsection{Swivel joint seal replacement and cable replacement test}

WD\&C mock lay-down area activities were not performed because there were no failures during cold testing that required lay-down of the WD\&C. However, joint seal replacement was performed in place. Cable replacement was not performed.

\subsubsection{Summary of Test Results}

No failures occurred during cold testing that necessitated a repair significant enough to require lay down of the WD\&C system. A number of routine maintenance and minor repair activities were completed in place that provided excellent training opportunity.

\subsection{SAMPLE COLLECTION TEST}

\subsubsection{Test Objectives}

The FCE/CB contains the proportional sampler that is intended to permit sample collection from the slurry line during operation. The testing contained in this section was used to evaluate the accuracy of the sampler during three-phase flow in the pipe. ${ }^{5}$ 
The objective of this test was to evaluate the ability of the proportional sampler to collect samples when the WD\&C system is experiencing three-phase flow.

\subsubsection{Testing Performed}

\subsubsection{Sample collection test}

This test procedure was deleted. The sampler was found to be accurate to within about $1 \%$ for samples obtained during liquid and dilute slurry transfers. For three-phase transfers, a sample was obtained that was proportional to the amount of air entrained in the transfer line.

\subsubsection{Summary of Test Results}

The Isolok sampler worked well for liquid and slurry transfers, consistently obtaining a $10-\mathrm{mL}$ sample with each stroke. The sampler successfully obtained a sample during three-phase transfers but obtained less than a 10-mL sample obtained per stroke. 
- 42 - 


\section{OVERVIEW CAMERA AND LIGHTING SYSTEM TESTING}

\subsection{OVERVIEW CAMERA AND LIGHTING TESTS}

\subsubsection{Test Objectives}

The overview camera and lighting tests were performed for the overview camera and lighting equipment that will be used during NTF operations. These tests are unrelated to the WD\&C performance tests, and as such, could be performed at any time. This section details the test activities. $^{6}$

These tests included all activities to install, check out, and operate the overview camera and lighting systems that will be used during the NTF operations. These activities were conducted in accordance with previously developed written procedures. Overview camera and lighting tests could occur in conjunction with WD\&C testing activities. The specific tests and the objectives of the camera and lighting tests are listed in Table 5.1.1.

Table 5.1.1 Overview camera and lighting test objectives

\begin{tabular}{|c|c|}
\hline Test & Objective \\
\hline \multirow[t]{2}{*}{ Installation } & $\begin{array}{l}\text { Verify that installation procedures are adequate and } \\
\text { complete. }\end{array}$ \\
\hline & Document the time required to complete installation. \\
\hline \multirow[t]{2}{*}{ Equipment checkout } & Verify that checkout procedures are adequate and complete. \\
\hline & $\begin{array}{l}\text { Document the time required to complete equipment } \\
\text { checkout. }\end{array}$ \\
\hline \multirow[t]{3}{*}{ Operations } & $\begin{array}{l}\text { Verify that operations procedures are adequate and } \\
\text { complete. }\end{array}$ \\
\hline & $\begin{array}{l}\text { Demonstrate the manual and automatic camera focus } \\
\text { requirement for effective and repeatable focusing ability } \\
\text { from a remote location. }\end{array}$ \\
\hline & $\begin{array}{l}\text { Define effective placement of lights for the ability to view all } \\
\text { locations within the tank during operations. }\end{array}$ \\
\hline Failure & $\begin{array}{l}\text { Demonstrate the maintenance requirements for failed camera } \\
\text { and lighting equipment. }\end{array}$ \\
\hline
\end{tabular}

\subsubsection{Testing Performed}

5.1.2.1 Camera and lighting equipment installation, checkout, and removal test

The test procedure was followed and completed successfully.

5.1.2.2 Camera and lighting operations test

The test procedure was followed and completed successfully. 


\subsubsection{Camera and lighting maintenance}

The test procedure was followed and completed successfully.

\subsubsection{Summary of Test Results}

The installation work instructions and operating procedures were validated as being adequate and complete, and the total installation time was approximately 15 minutes. The cameras were determined to meet all project requirements. 


\section{CHARACTERIZATION END-EFFECTOR TESTING}

\subsection{CHARACTERIZATION END-EFFECTOR (CEE) TESTS}

\subsubsection{Test Objectives}

The CEE tests were performed for the radiation survey equipment that will be used during NTF operations.

These tests included all activities to install, check out, and operate the CEE that will be used during NTF operations. The specific tests and the objectives of the CEE tests are listed in Table 6.1.1.

A major change in scope consists of no longer using the drilling function specified in the functions and requirements document.

Table 6.1.1 Characterization end-effector test objectives

\begin{tabular}{ll}
\hline \multicolumn{1}{c}{ Test } & \multicolumn{1}{c}{ Objective } \\
\hline $\begin{array}{l}\text { Instrumentation accuracy } \\
\text { Grasping by robots }\end{array}$ & Verify instrumentation accuracy. \\
$\begin{array}{l}\text { Deployment via tether } \\
\text { handling system }\end{array}$ & Verify deployment via the tether handling system. \\
$\begin{array}{l}\text { Operation of user interface } \\
\text { Equipment precheckout }\end{array}$ & Verify operation of the user interface. \\
$\begin{array}{l}\text { Walkdown of operations } \\
\text { procedures }\end{array}$ & Conduct a precheckout of the equipment. \\
\hline
\end{tabular}

\subsubsection{Testing Performed}

\subsubsection{CEE instrumentation accuracy}

The ORNL Office of Radiation Protection calibrated the radiation instruments in their facility. Their quality assurance procedures were used for the calibration. The calibrations of the Eberline RO-7 and SRM200 instruments were performed successfully.

The cadmium zellurium telluride sensor was calibrated using an $241 \mathrm{Am}$. source to generate a reference spectrum. Operation was successful.

\subsubsection{CEE grasping by robots}

Grasping by robots is covered by the operating procedures for the respective robots. These operations were successfully practiced using the MLDUA and ROV robots, and the robot operators recorded the results. 


\subsubsection{CEE deployment via tether handling system}

Operation with the THS was successfully tested as a part of testing the CEE for grasping by the robots. Operation was successful.

\subsubsection{Operation of the CEE user interface}

The CEE operation via the WD\&C control station was tested. Operation was successful.

\subsubsection{CEE precheckout of equipment}

Equipment checkout was practiced using $90 \mathrm{Sr} 90$ and $241 \mathrm{Am}$. sources to verify that the instruments were operational just before entering the tanks. This operation is via the glove ports in the THS, and the operation takes about 10 minutes. Operation was successful.

\subsubsection{CEE operations procedures checkout}

The operating procedures were walked down and practiced, and any necessary changes were made. The procedures were tested successfully and were found to be adequate and complete.

\subsubsection{Summary of Test Results}

During initial testing of the CEE, it was discovered that the technology used for drilling into the Gunite walls was not adequate for the task. Not only was the drilling progress slow, but in addition, the attempted drilling vibrated the radiation sensors and eventually damaged them. The decision was made to discontinue use of the drill and instead design a new end effector that collected wall samples using a coring tool. This new "coring tool" is not considered part of the CEE and therefore is described in a separate document. 


\section{CONCLUSIONS}

The GAAT remotely operated tank waste retrieval system was assembled at the ORNL TTCTF for a series of cold tests that demonstrated the feasibility of removing sludge waste from underground storage tanks. Components of the system started arriving on site in May 1996. By November 1996 essentially all components of the system were on site and were installed at the TTCTF. A series of open-house demonstrations was conducted in December 1996. From January through early May 1997, the GAAT project team focused on completion of the graphical user interface and control system to allow remote control of the process system and on operator training and validation of operating procedures.

The test program described in this report served as a framework to guide the cold test activities. A number of the planned activities were modified or deleted once some operational experience with the equipment identified the most valuable test activities. The cold test program was tremendously valuable for preparing the project team and equipment for the three-to-five-year-long operational phase in the NTF and STF. The successful development and demonstration of this system was achieved through unprecedented cooperation between the ORNL Environmental Restoration Program and several DOE Technology Development organizations, including the Tanks Focus Area, Robotics Technology Development Program, and Federal Energy Technology Center Industry Program. 
- 48 - 


\section{REFERENCES}

1. Gunite and Associated Tanks Operable Unit Baseline Report and Treatability Study Work Plan, Oak Ridge National Laboratory, Oak Ridge, Tennessee, DOE/OR/02-1325\&D2, Jacobs ER Team, October 1995.

2. B. L. Burks et al., "A Remotely Operated Tank Waste Retrieval System for ORNL," Radwaste Magazine, 4(2) 10-16 (March 1997).

3. Treatability Study Operational Testing Program and Implementation Plan for the Gunite and Associated Tanks at the Oak Ridge National Laboratory, Oak Ridge, Tennessee, ORNL/ER361/R1, XL Associates, September 1996.

4. Modified Light Duty Utility Arm and Integrated System Performance Test Plan for the Gunite and Associated Tanks Treatability Study at Oak Ridge National Laboratory, Oak Ridge, Tennessee, 96094P-WP6/103196, Science Applications International Corp., Lockheed Martin Energy Systems, Inc., Lockheed Martin Energy Research Corp., XL Associates, October 1996.

5. Remotely Operated Vehicle and Integrated System Test Plan, XL Associates, Inc., Lockheed Martin Energy Research, Lockheed Martin Energy System, ENSR Consulting and Engineering, Inc., LMES Subcontract Number 18X-JFA82C, October 4, 1996.

6. Waste Dislodging and Conveyance System and Auxiliary Equipment Performance Test Plan, XL Associates, Inc., Lockheed Martin Energy Research, Lockheed Martin Energy System, ENSR Consulting and Engineering, Inc., LMES Subcontract Number 18X-JFA82C, October 15, 1996. 
ORNL/TM-13629

\section{INTERNAL DISTRIBUTION}

1. J. P. Abston, Bldg. 1062, MS 6420

2. D. H. Boling, Bldg. 7078-B, MS 6402

3. D. C. Dunning, Bldg. 7601, MS-6304

4. C. L. Fitzgerald, Bldg. 7601, MS 6304

5. O. W. Hale, Bldg. 1000, MS-6338

6. D. C. Haley, Bldg. 7601, MS 6305

7. J. N. Herndon, Bldg. 7601, MS 6305

8. D. E. Hobson, Bldg. 7601, MS-6304

9. B. E. Lewis, Bldg. 7601, MS 6306

10. M. A. Johnson, MS-6342

11. S. M. Killough, Bldg. 7606, MS 6426

12. D. J. Kington, Bldg. 7601, MS 6305

13. P. D. Lloyd, Bldg. 7606, MS 6426

14. J. A. Miller, Bldg. 2652-B, MS 6290

15. T. E. Myrick, Bldg. 1000, MS 6296

16. K. E. Plummer, Bldg. 7601, 6306

17. J. D. Randolph, Bldg. 7601, MS 6306

18. $\quad$ S. L. Schrock, Bldg. 7601, MS 6304

19. H. Toy, Bldg. 7606A, MS-6426

20-45. D. Van Hoesen, Bldg. 1000, MS 6338

46. Central Research Library, Bldg. 4500N, MS 6285

47. ORNL Library Records - RC, Bldg. 4500N, MS 6285

48. ORNL Library Records - OSTI, Bldg. 4500N, MS 6285

\section{EXTERNAL DISTRIBUTION}

49. S. Bailey, Pacific Northwest National Laboratory, P.O. Box 999, KS-08, Richland, WA 99352

50. G. Boyd, U.S. Department of Energy, Office of Science and Technology, EM-50, 1000 Independence, Avenue, SW, Washington, DC 20585

51. T. Brouns, Pacific Northwest National Laboratory, P.O. Box 999, K9-91, Richland, WA 99352

52-87. B. L. Burks, The Providence Group, P.O. Box 23408, Knoxville, TN 37933-1408

88. B. Carteret, Pacific Northwest National Laboratory, P.O. Box 999, K9-91, Richland, WA 99352

89. C. Christensen, LITCO, P.O. Box 1625, 3211, Idaho Falls, ID 83415-3710

90. J. DeGregory, U.S. Department of Energy, 19901 Germantown Road, Germantown, MD 20874-1290

91-95. J. Emisson, XL Associates, 677 Emory Valley Road, Suite C, Oak Ridge, TN 37830

96. D. Green, DOE-Oak Ridge Operations Office, P.O. Box 2001, Oak Ridge, TN 37831

97. T. Pietruk, U.S. Department of Energy-Richland Operations Office, 825 Jadwin Avenue, Room 1622, Richland, WA 99352

98. P. Gibbons, Numatec Hanford Company, P.O. Box 1300, H6-12, Richland, WA 99352-1300

99. T. Gutmann, U.S. Department of Energy, Savannah River Operations Office, P.O. Box A, Bldg. 704S, Aiken, SC 29802

100. F. Hazen, Robotics Home Office, 576 East End Avenue, Pittsburgh, PA 15221

101. R. M. Hollen, Los Alamos National Laboratory, P.O. Box 1663, MS J580, Los Alamos, NM 87545

102. J. Honeyman, LMHC, P.O. Box 1500, G3-21, Richland, WA 99352

103. V. J. Kothari, Federal Energy Technology Center, P.O. Box 880, Morgantown, WV 260570880

104. J. Morin, Westinghouse Savannah River Company, Savannah River Technology Center, Bldg. $103 \mathrm{H}$, Aiken, SC 29801 
105. J. Noble-Dial, U.S. Department of Energy, Oak Ridge Operations Office, P.O. Box 2001, Oak Ridge, TN 37831

106. M. Rinker, Pacific Northwest National Laboratory, P.O. Box 999, K5-22, Richland, WA 99352

107. E. Saldivar, Westinghouse Savannah River Company, Bldg. 742-4G, Room 1, Aiken, SC 29801

108. S. Tibrea, Westinghouse Savannah River Company, Savannah River Technology Center, Bldg. 773-A, D-1132, Aiken, SC 29808

109. J. Valentine, LITCO, P.O. Box 1625, 3211, Idaho Falls, ID 83415-3100

110. D. Wadsworth, Idaho National Engineering and Environmental Laboratory, P.O. Box 1625, MS 2220, Idaho Falls 83415-2220

111. J. Walker, U.S. Department of Energy, Headquarters, 19901 Germantown Road, Germantown, MD 20874 